\title{
Palestinian strategies, guidelines, and challenges in the treatment and management of coronavirus disease-2019 (COVID-19)
}

\author{
Hatem A. Hejaz \\ College of Pharmacy \& Medical Sciences, Hebron University, Hebron, Palestine
}

\begin{tabular}{|c|}
\hline Access this article online \\
\hline Website: www.avicennajmed.com \\
\hline DOI: 10.4103/ajm.ajm_171_20 \\
\hline Quick Response Code: \\
\hline
\end{tabular}

Address for correspondence: Dr. Hatem A Hejaz,

College of Pharmacy \& Medical Sciences, Hebron University,

P.O. Box 40, Hebron, Palestine.

E-mail: hhejaz@hebron.edu

\section{ABSTRACT}

Background: Coronavirus disease-2019 (COVID-19) outbreak is a global concern and the World Health Organization (WHO) has declared it as a Public Health Emergency of International Concern. The Palestinian Authority (PA) has quickly and effectively responded to the outbreak of COVID-19, using an internationally and nationally coordinated, to contain the spread of the virus within the borders. The PA approaches are containment and suppression, which is designed to protect the citizens from infection while also mitigating the stress on the health care system. The PA immediately declared a State of Emergency when the first cases in Palestine were diagnosed on 5 March 2020 and launched robust national containment measures to encourage the citizens to protect themselves and follow the guidance. Objectives: There is currently no vaccine or effective treatment for COVID-19, the treatment is either supportive and/ or the treatment of symptoms. Several strategies in the treatment of the disease were applied including medications. This review aims to summarize the different strategies, guidelines, challenges, and treatments used against COVID-19 worldwide and in Palestine. Materials and Methods: Different literature and guidelines among different databases were searched. Literature reviewing was conducted using the following search engines, Google Scholar, Medline, Pub Med, EMBASE, Web of Science, and Science Direct. Data also obtained from WHO and PA reports, and the published peer-reviewed articles of 2019-nCoV. The review focuses on the strategies, guidelines, therapeutics, challenges, and different approaches used in the treatment and management of the disease in Palestine and globally. Conclusion: The Palestinian Ministry of Health $(\mathrm{MoH})$ strategies to end the COVID-19 pandemic were; slow and stop transmission; provide optimized care for patients; and minimize the impact of the epidemic on health systems, social services, and economic activity. Thus, proper management, right actions, and effective treatment of the disease should be considered to achieve these strategies. The biggest problem for PA to control and stop the outbreak of the disease is the different challenges which include; the Israeli military and economic control, uncontrol the borders, shortage of medical and financial resources, crowded cities and refugee camps, poverty, food insecurity, and the financial crisis. To date, there are no specific vaccines or medicines for COVID-19; and treatments are under investigation through clinical trials. However, an array of drugs approved for other indications, as well as multiple investigational agents, are being studied for the treatment of COVID-19; in several hundred clinical trials around the World. Treatment is essentially supportive and symptomatic. 


\section{INTRODUCTION}

Coronavirus disease-2019 (COVID-19) is a serious public health crisis threatening the world with extremely fast spread and mortality. The COVID-19 pandemic indisputably amounts to an unprecedented global public health challenge in the twenty-first century. It caused many consequences of socioeconomic, political, and public health worldwide. Many addressed the economic repercussions of the coronavirus, especially in the absence of confirmed news about the creation of an effective medical drug to combat it, as well as the close link between the global economy and the Chinese economy, which makes any tremors experienced by the latter with serious global consequences. Some have highlighted conspiracy theories related to the emergence of the virus and the rumors that spread fears, which in turn will reflect on the economy of countries. Although some warn of the impact of rumors, others have promoted a theory that corona is a "biological weapon." Coronaviruses are enveloped positivesense RNA viruses ranging from 60 to $140 \mathrm{~nm}$ in diameter with spike-like projections on its surface giving it a crownlike appearance under the electron microscope; hence the name coronavirus. Four coronaviruses namely HKU1, NL63, 229E, and OC43 have been in circulation in humans and generally cause mild respiratory disease. The COVID-19 pandemic has exploded as cases have been identified as the cause of an outbreak of respiratory illness in Wuhan, Hubei Province, China at the beginning of December 2019. As of 31 January 2020, this epidemic had spread to 19 countries with 11791 confirmed cases, including 213 deaths. The disease is transmitted by inhalation or contact with infected droplets and the incubation period ranges from 2 to 14 days or even more. The most common symptoms are fever, dry cough, and tiredness, whereas the serious symptoms are difficulty breathing or shortness of breath, chest pain or pressure, and loss of speech or movement. There are also less common symptoms such as; aches and pains, sore throat, diarrhea, conjunctivitis, headache, loss of taste or smell, and a rash on the skin, or discoloration of fingers or toes. The disease may progress to pneumonia, acute respiratory distress syndrome (ARDS), and multiorgan dysfunction especially in elderly people and those with comorbidities. However, symptoms of a coronavirus usually go away on their own and many people are asymptomatic. The virus is diagnosed in respiratory secretions by special molecular tests. In some cases, selfisolate to prevent the spread of infection is preferred and advisable. There is no specific treatment for disease caused by a coronavirus. However, many of the symptoms can be treated and therefore treatment based on the patients' clinical conditions. The World Health Organization (WHO) has declared it a Public Health Emergency of International Concern. By June 4, 2020, more than 6.5 million cases of COVID-19 have been reported globally, including $>380,000$ deaths. Cases caused by severe acute respiratory syndrome coronavirus 2 (SARS-CoV-2) infections have been reported in more than 180 countries, including all 50 states of the United States. ${ }^{[1-3]}$

On February 22, 2020, the Palestinian Ministry of the Interior closed several restaurants in Palestinian cities as a result of the visit by a Korean delegation after some of its members were confirmed with the infection of the coronavirus 2019. The COVID-19 pandemic was confirmed to have spread to the West Bank on March 5, 2020 and the Palestinian $\mathrm{MoH}$ said the cases had first been detected at a hotel in the Bethlehem area, where a group of Greek tourists had visited the hotel in late February, with two later diagnosed with the virus. Although in the Gaza Strip, the first case was diagnosed in Gaza on March 21, and as of July 4,2020 , there were about 11 active cases and one death. On March 29, 2020, the Palestinian MoH confirmed 11 new cases in the West Bank, and on March 30 an additional 7 new cases were also confirmed. No new cases were reported for Gaza in this period. By March 30, 2020, the confirmed cases were 115 cases (West Bank 106 and Gaza Strip 9 cases). The highest cases were in Bethlehem (46 cases). By this time, the $\mathrm{MoH}$ has reported a total of 18 cases have recovered and one person had died. Most cases do not present clinical symptoms and none are critical. All new cases were under medical observation at designated health facilities and contact tracing was initiated for all cases. The East Jerusalem Hospital Network has also announced preparations for Jerusalem hospitals to deal with cases of COVID-19 that require clinical care. In the Gaza Strip, the local health authorities have expanded the laboratory monitoring process to include hundreds of samples for quarantine inmates and contacts of patients with COVID-19 in quarantine centers since the beginning of March 2020. In this period, more than 1760 people were in one of 25 designated quarantine facilities including at Rafah crossing quarantine center or at health facilities, schools, or hotels designated as quarantine facilities. The quarantine period was $2-3$ weeks ( 21 days). Those coming from crossings at Rafah or Erez have been quarantined since March 15 . 
Home quarantine ended 26 March for those who entered Gaza 14 days prior. The $\mathrm{MoH}$ has limited public primary healthcare service delivery in the Gaza Strip, to 14 centers distributed across the five governorates, which provided essential services only, and one school per governorate was also assigned to serve as a triage center for respiratory cases. On 26 March 2020, the Palestinian Authority (PA) released the National COVID-19 Response Plan that outlined the strategic measures from several key sectors, including health, economy, and social protection to contain the outbreak. $^{[4-6]}$ As of April 23, a total of 480 Palestinians (including East Jerusalem) have been confirmed to have COVID-19, 319 in the West Bank, 17 in the Gaza Strip and according to the Palestinian $\mathrm{MoH}$, another 144 known cases in East Jerusalem, although uncertainty remains over the figures due as East Jerusalem has been covered by the Israeli authorities. Four of these people (all in the West Bank) died and at least 92 have recovered as shown in Figure 1. Approximately $80 \%$ of people detected positive are below the age of 50, the vast majority of whom are asymptomatic. Although the apparent spread of the virus by this period was limited compared to other countries, this may reflect the limited testing capacity, with slightly over 26,000 samples were tested only. Figure 1 shows also quarantine centers, crossing points, and closed crossing points in this period. The PA was leading the efforts to contain the pandemic, in coordination with the Israeli authorities and international actors, primarily the WHO. ${ }^{[4-6]}$

Although on May 28, 2020, the pandemic cases were $5,868,922$ and 360,476 deaths worldwide with a $6.14 \%$ mortality rate, and in Palestine, the pandemic confirmed cases were 570 with 4 deaths only. The disease spread extremely very fast as by the end of June (within only 1 month period), the cases have been nearly doubled as the coronavirus cases confirmed were 10,690,566, deaths $516,393(8 \%)$, and recovered are 5,856,464 worldwide. The high incidence rate and cases were in the USA $(2,751,571)$, then Brazil $(1,426,913)$, Russia $(654,405)$, India, UK, Spain, Peru, Chile, Italy, and Iran $(230,211)$, respectively . In Palestine by this time, at the end of June, the reported cases were increased very sharply by about six times; as more than 3,095 cases were reported including East Jerusalem (337 cases), with 11 deaths. The highest cases (1947 cases) were in Hebron Governorate; with these confirmed cases Palestine ranked 97 among 215 countries that have coronavirus; with the highest outbreak rate in the world; compare to population number. The city of Hebron is the epidemic center, with 3,773 active cases as of July 8, 2020, and 15 deaths. The outbreak of the disease globally was continued raising very sharp as by July 11,2020 , the coronaviruses cases reported was $12,872,339$ and the death cases were

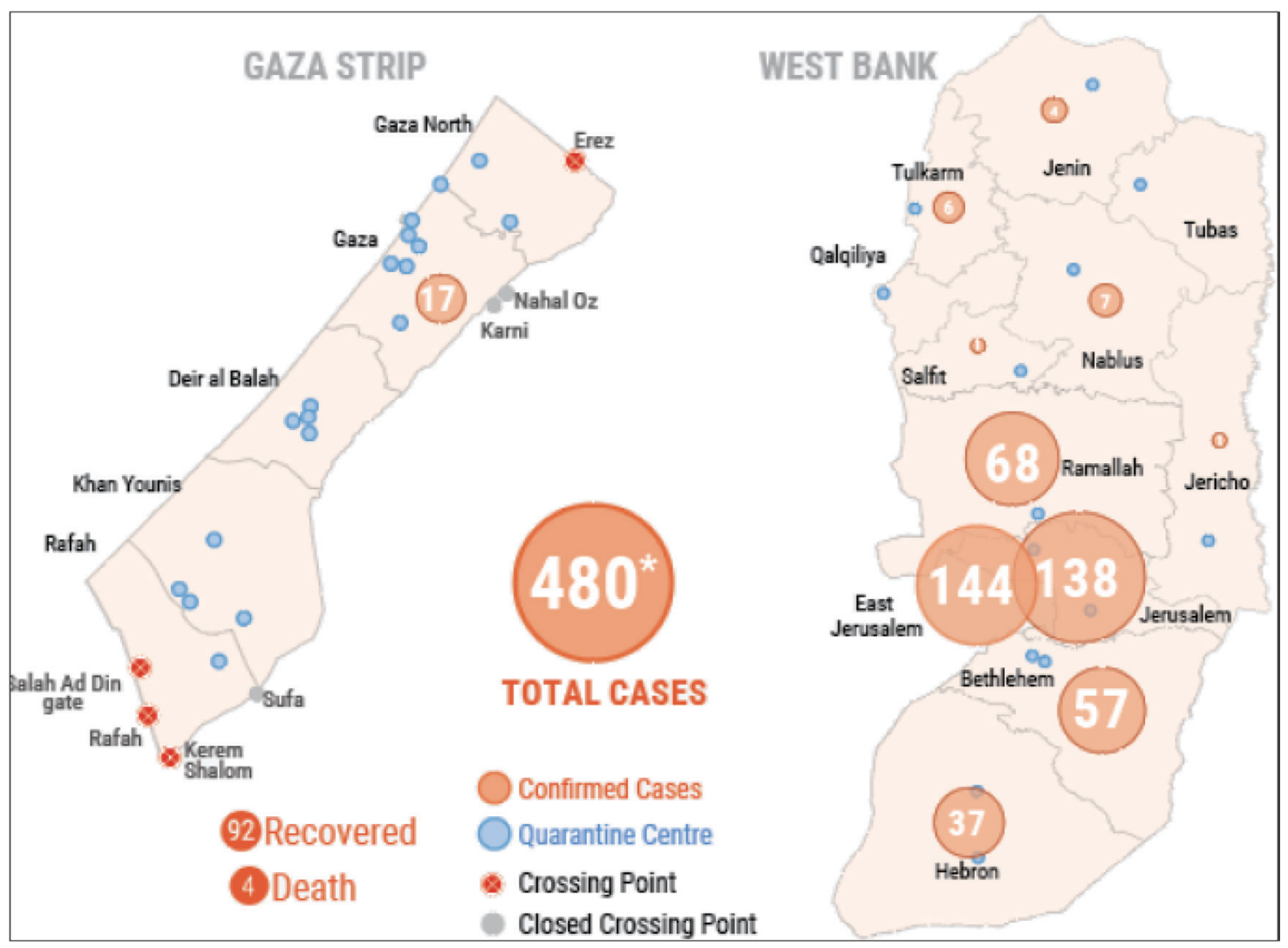

Figure 1: Coronavirus disease-2019 in Palestine by April 23, 2020 
568,312 , the increase rate of the new cases was $\sim 8 \%$ and the rate death increased by $1.125 \%$; within about 2 weeks period only, which considered high rates. The highest incidences by this time were in the USA with 3,356,242 reported cases, then Brazil $(1,840,812)$, India $(854,480)$, Russia $(727,162)$, and Peru $(322,710)$. In terms of the outbreak of the disease, the rank of the countries is changing every day, but the USA and Brazil remain and still rank first and second, respectively, for a while. In Palestine by July 11, 2020, the confirmed cases were 6688 , and the death cases were 36 , with an increased rate of $304 \%$, which extremely very high and considered the highest worldwide. The highest cases were in Hebron Governorate (4620 cases), with about $70 \%$ of the total reported cases, with these confirmed cases Palestine ranked 87 among 215 countries that have coronavirus; with the highest outbreak rate in the world too; compare to population number. Within only 2 weeks period the Palestine rank changed from 97 to 87; however, if the outbreak in Palestine remains rising by the same rate, Palestine after a short period will be one of the top countries having the disease, if real and serious precautions did not apply especially the health recommendations, isolation and maintain social distance. The high outbreak of the disease in this region (Hebron Governorate), as $90 \%$ of infections have been caused by people meeting up with their families or attending wedding parties or funerals and failing to follow health recommendations and maintain social distancing according to Palestinian MoH officials. ${ }^{[4-6]}$ (https://www. worldometers.info/coronavirus/). The number of people testing positive for COVID-19 continues to surge in the West Bank with an average of 396 new cases per day since July 1 . On July 23, the occupied Palestinian territory (oPt) experienced a record number of confirmed cases in one day at 596. The WHO risk assessment remains very high for the oPt. The number of people testing positive for SARS-CoV-2 continues to increase. The total number of cases is 11,875 including 11,800 cases in the West Bank and 75 in the Gaza Strip, with three new cases reported in Gaza in this period. From July 1 (to July 23) the West Bank (including East Jerusalem) has averaged 396 cases per day, with 9,110 new cases and 61 fatalities. Most cases recorded are from Hebron (6,789), East Jerusalem (2,131), Jerusalem (784), Ramallah (654), Bethlehem (576), Nablus (339), and Qalqilya (143). Other governorates (Salfit, Tubas, Tulkarm, and Jenin) continue to record low case numbers. A total of 81 health workers are among those confirmed cases and 16 patients are in a serious condition, with four patients requiring mechanical ventilation (as of 23 July). By this period, the $\mathrm{MoH}$ reported a total of 3394 cases have recovered; 3326 in the West Bank (including 674 in East Jerusalem) and 68 in Gaza and seventy people have died, with an overall case fatality rate (CFR) of $0.59 \%$. Less than half ( $47 \%$ ) of all confirmed cases are male (4,388 cases) and about $81.6 \%$ of all cases (7,332 cases) are below the age of 50 years in the $\mathrm{oPt}$, excluding East Jerusalem. A total of 172,382 laboratory samples have been tested for COVID-19 according to the $\mathrm{MoH}$, with 13,634 samples tested in the Gaza Strip [Figure 2]. 23,261 Palestinians are in quarantine (home or facility-based) to prevent further spread of the disease. In the Gaza Strip, 259 people are in one of the key hospitals across the Gaza Strip on July 17 . The Centers are designed to ensure that all suspected patients with COVID-19 are adequately assessed and managed, separate from other patients in emergency departments to ensure containment and prevent further spread of COVID-19. As of July 23 (noon), the PA $\mathrm{MoH}$ reported 2,131 COVID-19 cases in East Jerusalem. Three deaths have been reported (CFR: $0.14 \%$ ) and 174 have recovered in the same period. As of July 20, 16 patients are being treated in three designated COVID-19 hospitals in East Jerusalem including five patients at Augusta Victoria Hospital, seven at St. Joseph Hospital, and four at Makassed Hospital. Over the past 2 weeks up to July 22, Makassed Hospital received 14 patients with COVID-19, discharged 12 , and 2 have recovered. In these designated hospitals in East Jerusalem, 19 health workers have tested positive for COVID-19 and 35 are under quarantine (as of July 22). ${ }^{[4-6]}$

On August 3, 2020, 10:28 GMT the confirmed cases are 18,258,448, Deaths: 693,395, and Recovered: 11,460,069 worldwide. After about 3 weeks the number increased sharply by $5,386,109$ cases, about $42 \%$ increased, which is high. The USA $(4,813,984)$ and Brazil $(2,733,677)$ are the highest in the world; ranked first and second with increased percentage $\sim 43 \%$ and $\sim 48.5 \%$, respectively, within about 3 weeks only. It clear that the outbreak of the disease increased very fast globally. In Palestine, the cases also raised sharply; by $\sim 136 \%$ increased within 3 weeks period too, the case increased from 6668 to 15780 cases, which extremely very high [Figure 3]; by this increased rate Palestine ranked 74 out of 215 countries have the disease. Figure 3 shows COVID-19 in oPt by August 2, 2020, cumulative confirmed, recovered and death cases, confirmed cases per day (since April to August 2020), confirmed cases by gender (March 5 to July 26, 2020), and confirmed cases by age in Palestine. Some data reported were included and some excluded East Jerusalem. (http://www.emro.who.int/pse/palestine-news/ top-story.html). Table 1 shows cases for the top 30 countries including, other information such as daily new cases, total death, totally recovered, and a total test of each country. Although the actual and accurate causes and effective treatment of COVID-19 are still unknown or unavailable and the number of active cases of the infection is rising every 


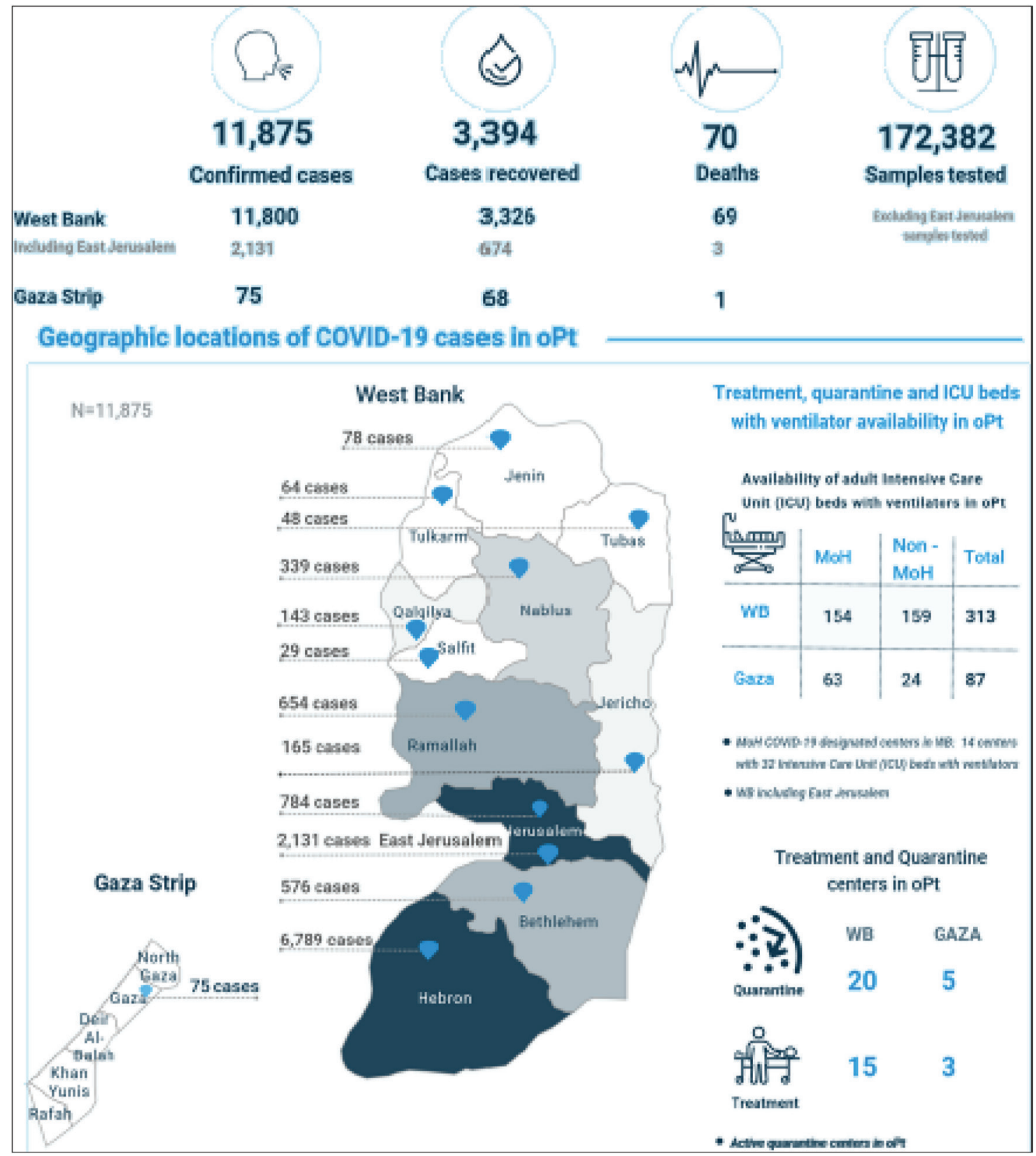

Figure 2: Geographic location of COVID-19 in Palestine by July 23, 2020 (excluding East Jerusalem)

day as mentioned, which rising panic and concern on public health worldwide. Prevention is still the best strategy to face this pandemic. These numbers are possibly an underestimate of the infected and dead due to limitations of surveillance and testing. It is though the SARS-CoV-2 originated from bats, the intermediary animal through which it crossed over to humans is uncertain. Pangolins and snakes are the current suspects. ${ }^{[7]}$

The onset and duration of viral shedding and the period of infectiousness are not completely defined. The estimated incubation period for COVID-19 is up to 14 days from the time of exposure or even more, with a median incubation period of 4 to 5 days. ${ }^{[8-10]}$ The disease is transmitted by inhalation or contact with infected droplets. The spectrum of illness can range from asymptomatic infection to severe pneumonia with ARDS. ${ }^{[7]}$ In a report of 1,482 hospitalized patients with confirmed COVID-19 in the United States, the most common presenting symptoms were cough (86\%), fever or chills (85\%), and shortness of breath (80\%), diarrhea (27\%), and nausea (24\%). ${ }^{[1]}$ Other reported symptoms have included, but are not limited to, sputum production, headache, dizziness, rhinorrhea, anosmia, dyspepsia, sore throat, abdominal pain, anorexia, and vomiting. Asymptomatic or pre-symptomatic individuals infected with SARS-CoV-2 may have viral RNA detected in 


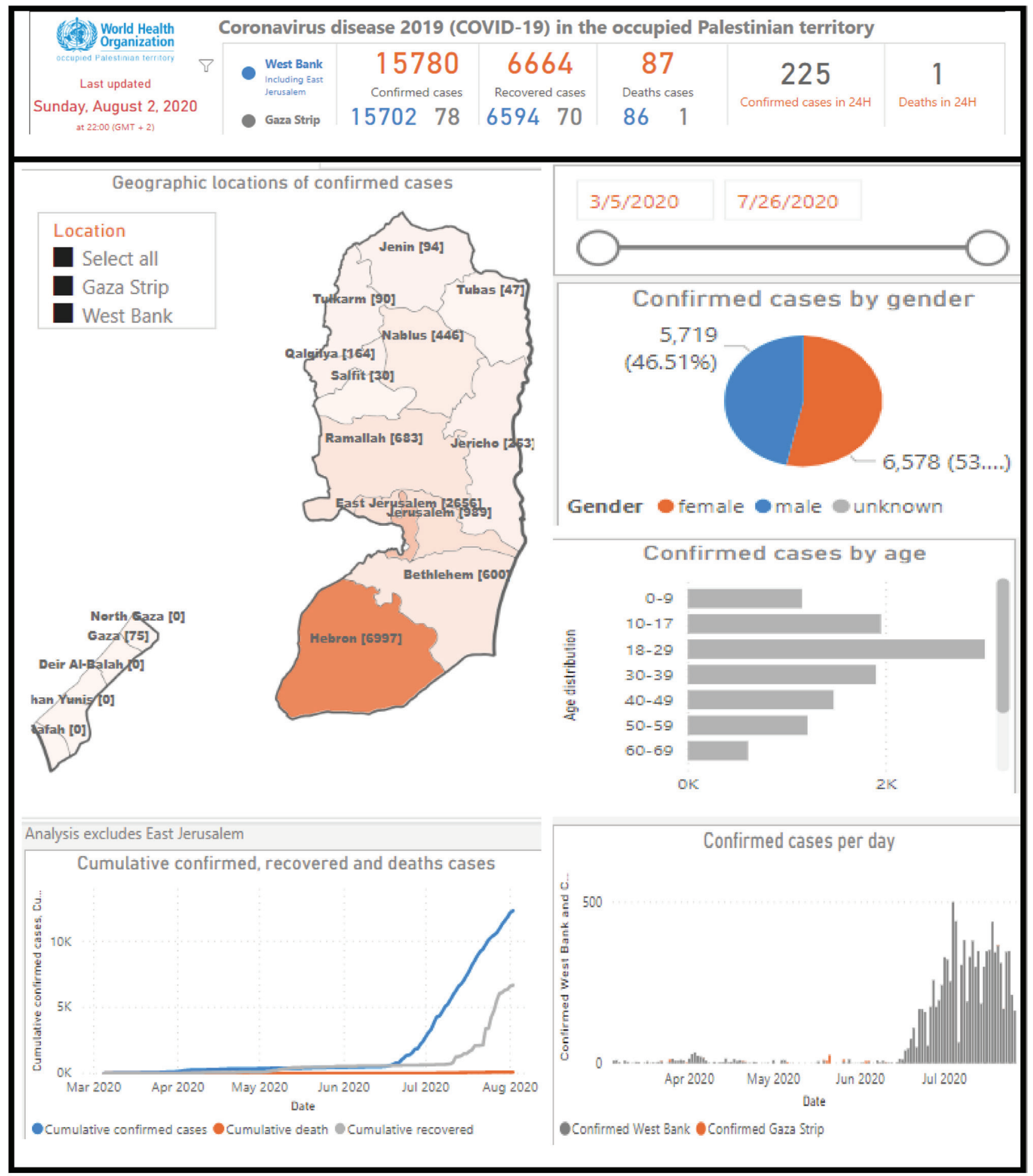

Figure 3: Coronavirus disease-2019 in Palestine

(Source: http://www.emro.who.int/pse/palestine-news/landing-page-for-covid19.html)

upper respiratory specimens before the onset of symptoms. Transmission of SARS-CoV-2 from asymptomatic individuals has been described. ${ }^{[12-14]}$ The extent to which this occurs remains unknown. Individuals of all ages are at risk for infection and severe disease. The probability of fatal disease is highest in people aged $\geq 65$ years and those living in a nursing home or long-term care facility. However, others at the highest risk for COVID-19 are people of any age with certain underlying conditions, especially when not well-controlled, including hypertension, cardiovascular disease, diabetes, chronic respiratory disease, cancer, renal disease, and obesity. ${ }^{[15-18]}$ 


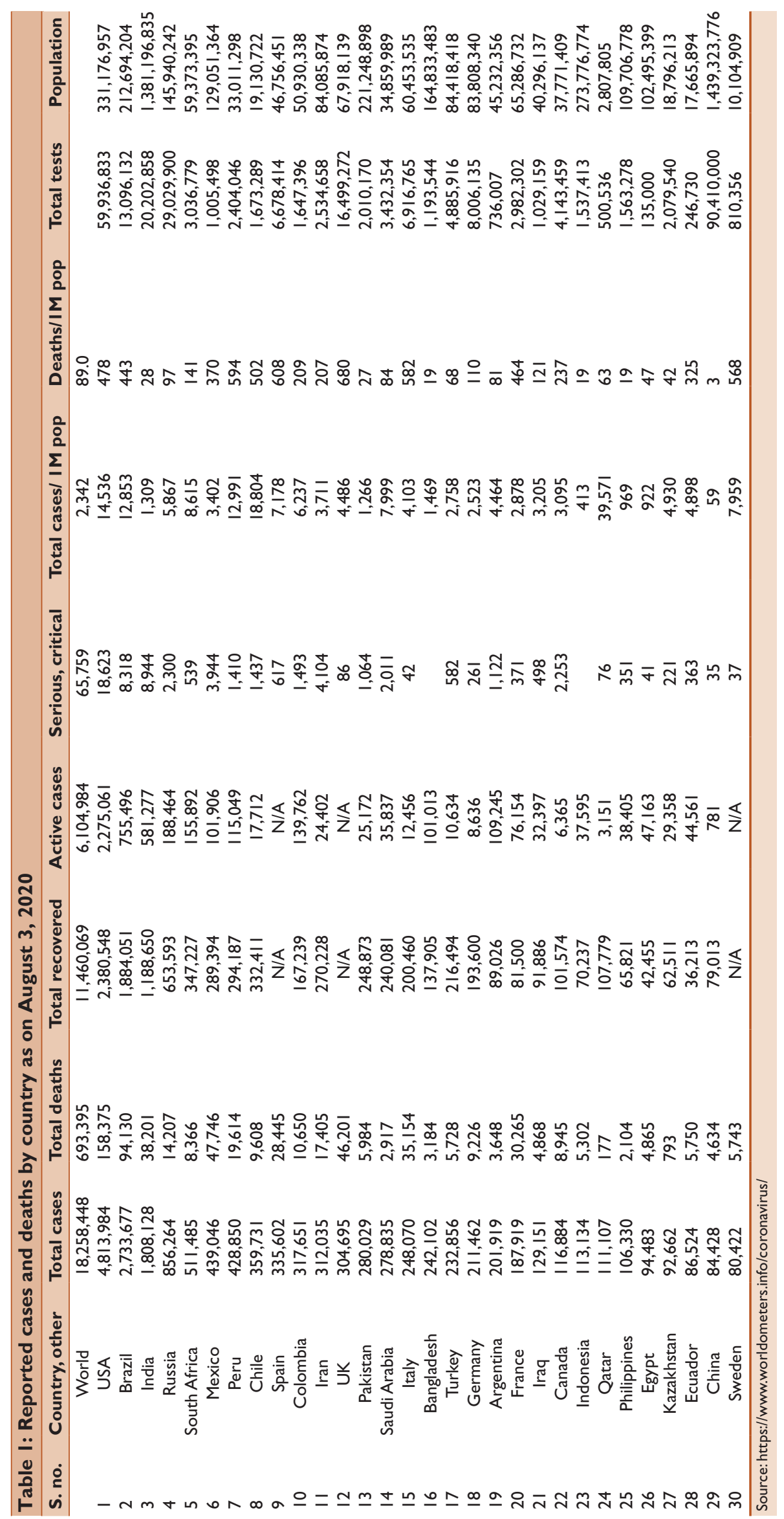


Common laboratory findings of COVID-19 include leukopenia and lymphopenia. Other laboratory abnormalities have included elevations in aminotransferase levels, include normal/ low white cell counts with elevated C-reactive protein (CRP), D-dimer, ferritin, and lactate dehydrogenase, $\mathrm{X}$-ray, and computerized tomographic. The CT chest scan is usually abnormal and varies even in those with no symptoms or mild disease. Imaging may be normal early in infection and can be abnormal in the absence of symptoms. ${ }^{[19]}$ Every year an estimated 290,000 to 650,000 people die in the world due to complications from seasonal influenza (flu) viruses. There are about 795 to 1781 deaths per day due to the seasonal flu. SARS (November 2002 to July 2003). The coronavirus that originated from China and spread to different countries; resulted in more than ten and a half million people infected; and with about more than half a million deaths; with a fatality rate of $8 \%$, by end of June 2020. Thus, the rates of cases and death of coronavirus are most likely will be more than seasonal influenza viruses; especially the virus outbreak is rising sharply every day; thus, the fatality will higher. Treatment of the disease is essentially supportive; the role of antiviral agents is yet to be established. Prevention entails home isolation of suspected cases and those with mild illnesses and strict infection control measures at hospitals that include contact and droplet precautions. The virus spreads faster than its two ancestors the SARS-CoV and Middle East respiratory syndrome coronavirus (MERS-CoV) but has lower fatality till now. The global impact of this new epidemic is yet uncertain. Treatment is mainly supportive as no antiviral has been approved yet. Efforts are being made to find effective treatment and to reduce the virus outbreak. However, not much information is known about the virus causes, its survival period, methods of its spreading, biochemical and hematological disorders, its complications, its prevention, and treatments. Everyone talks about Covid-19, and wherever you look you find information about the virus and how to protect yourself from it. Knowing the facts is necessary to be adequately prepared to protect yourself and your loved ones. Unfortunately, much information is incorrect. The spread of misleading information during health crises leaves people unprotected and vulnerable to the disease and the spread of fear and stigma among them. Therefore, this review provides trustful information and data obtained from official reports and peer-reviewed journals. We mainly focused on the latest treatment and precautions of COVID-19 including the strategies, guidelines, and challenges against the disease globally and in Palestine. Slow and stop transmission; provide optimized care for all patients; and minimize the impact of the epidemic on health systems, social services, and economic activity are the main objectives for the management of the disease. More than 150 different drugs are being researched around the world. Most are existing drugs that are being tested against the virus. Here we also high light on the most important drugs used/or tested for the treatment of the disease and the disease complications. In Palestine, the treatment and management protocols of COVID-19 are similar to the strategies and protocols in the other countries which follow the guidelines of WHO. ${ }^{[5,7]}$

\section{MATERIALS AND METHODS}

The review discussed the different therapeutic strategies and drugs used for the treatment of COVID-19. Preciously, different literature and guidelines among different databases were searched, summarized, and discussed. The literature review was conducted using various search engines, Google Scholar, Medline, Pub Med, EMBASE, Web of Science, and Science Direct. Data also obtained from the WHO reports, and the published peer-reviewed articles of 2019 novel coronavirus (2019-nCoV). The initial terms "words" that match with the title or abstract or with the topic including 2019-nCoV, 2019 novel coronavirus, SARS, CoV2, COVID-19, COVID-19, NCP, and novel coronavirus, PA, pneumonia were used in searching the databases. The further search was also carried out using the keywords, SARS-CoV, severe acute respiratory syndrome, MERS, MERS-CoV, Middle East respiratory syndrome, in combinations of with "pike protein, genome, reproductive number, incubation period, fatality rate, clinical characteristics, pathology, autopsy, protocols, guidelines, treatment, and prevention. Moreover, official documents that have been released by the WHO were accessed for up to date data on COVID-19.

\section{RESULTS AND DISCUSSION}

COVID-19 is a serious public health concern worldwide, particularly in conflict settings, which face fragility, governance, and significant deficits in resources. Although some countries of the Middle East and North Africa (MENA) region have the resources to respond effectively to the COVID-19 pandemic, other countries in the region have insufficient resources and capacity to fight this pandemic, especially those under protracted conflicts such as Syria, Iraq, Yemen, and Palestine. The COVID-19 crisis has revealed major gaps in the social and public health systems in these countries, such as social exclusion, inequalities, fragility, unpreparedness, underinvestment, and weakness in governance and cooperation. The political situation in Palestine threatens the health security of Palestinians in the time of the pandemic and the 72 year-long ongoing Israeli 
control on Palestine is causing a dire humanitarian situation. The deteriorated living conditions in the West Bank, Gaza Strip and East Jerusalem including overcrowdedness, building restrictions, raids and arrests, home demolitions by Israel, absence of freedom of movement throughout Palestine, in addition to over 13 years of the siege on the Gaza strip, all impede Palestine's ability to control the spread of COVID-19. Moreover, the Water, sanitation, and hygiene (WASH) system infrastructure in Palestine has been destroyed as a result of Israel's regular attacks and its full control of all water resources in Palestine. The high levels of poverty and unemployment in Palestine (largely among refugees) means that they are unable to take necessary preventative measures against COVID-19. These humanitarian difficulties are expected to deteriorate further as a result of COVID-19. Local and international human rights and advocacy organizations must put pressure to end Israel's practices, mainly an immediate release of the imprisoned and besieged people who are at high risk. Palestinians are in a high need for financial and food support to alleviate the socioeconomic impacts of the pandemic and prevent any further economic collapses and food insecurity, especially among vulnerable populations including refugees and people in inaccessible areas. Although the political situation is complex and resources and capacities are limited, Palestine is outperformed many other countries in responding to COVID-19 especially at the beginning of the disease as the PA government was quick in imposing strict preventative lockdown measures. However, early relaxation of these measures could take away progress made and flare up the number of cases. Although authorities in the West Bank and Gaza Strip are following a restrict management approach to control COVID-19, their plans are still nonconsolidated. Yet, further coordinated efforts such as testing, tracing, public engagement, socioeconomic support packages are required for more efficient COVID-19 preparedness and response in Palestine. A more concise and unified response plan with a long-term vision including a robust exit strategy is essential for effectively combating the pandemic in Palestine. The response plan should include strategic directions; increased financial investments and efforts in strengthening the public health system's governance, capacity, and health research and surveillance. The emphasis on the importance of strengthening the national research system, improve the strategic components in all settings and conditions, and different novel means can help in building research capacity and emergency research of controlling the disease. Moreover, there is an urgent need to improve cooperation and collaboration between the different health actors in the West Bank, Gaza Strip, and East Jerusalem. This includes governmental, nongovernmental and private institutions and hospitals. Additionally, community participation and engagement in the response to COVID-19 are limited and need to be strengthened. Collective actions and investment strategy adopted by all state, nonstate actors, and regional and international humanitarian and development partners must become more efficient, systemic, and complementary to act into different trajectories which include; mobilizing all efforts and resources to the mitigation and containment measures to the COVID-19 pandemic; establishing a lockdown relaxation system conditional to local and national infection transmission rates; and re-thinking a post-pandemic strategy for strengthening the public health system taking into account health governance and policies, information system, advanced technologies, just resource allocation, and investment plans, health research system, and preparedness capacity. ${ }^{[4-6,20]}$

As the COVID-19 spreads, efforts are being made to reduce transmission via standard public health interventions based on isolation of cases and tracing of contacts. This contributes to reducing the size of the outbreak but cannot control the outbreak. ${ }^{[21]}$ Other interventions that were recommended to reduce the outbreak include strengthening emergency departments, application of strict hygiene measures for the prevention and control of infection, and avoidance of close contact with patients suffering from respiratory tract infections. Efforts are being made to find drugs and vaccines that act against SARS-CoV-2 to control the outbreak of the virus (vaccine is under development). Supportive care is the main strategy for treatment; such as control fever, maintenance of hydration and nutrition, and oxygen therapy. Up to $76 \%$ of patients with COVID-19 require oxygen therapy. Some patients require endotracheal intubation such as patients with hypoxemic respiratory patients. Other patients require oxygen supplementation to maintain an oxygen saturation between $90 \%-96 \%$. For patients who do not improve with oxygen therapy, high flow nasal cannula (HFNC) is recommended. ${ }^{[22-26]}$ Thus, the first step is to ensure adequate isolation to prevent transmission to other contacts, patients, and healthcare workers. Mild illness should be managed at home with counseling about danger signs. The usual principles are maintaining hydration and nutrition and controlling fever and cough. Routine use of antibiotics and antivirals such as oseltamivir should be avoided in confirmed cases. In hypoxic patients, the provision of oxygen through nasal prongs, face mask, HFNC, or noninvasive ventilation is indicated. Mechanical ventilation and even extracorporeal membrane oxygen (ECMO) support may be needed. Renal replacement therapy may be needed in some. Antibiotics and antifungals are required if co-infections are suspected 
or proven. The role of corticosteroids is unproven; although current international consensus and WHO advocate against their use, Chinese guidelines do recommend short term therapy with low-to-moderate dose corticosteroids in COVID-19 ARDS. Detailed guidelines for critical care management for COVID-19 have been published by the WHO. There is, as of now, no approved treatment for COVID-19. ${ }^{[23-26]}$ Due to the characteristics of this virus, as it has a long incubation period, the infection can be transmitted to many people before symptoms appear, so preventive measures are very necessary, so prevention is very important. The greatest danger is the transmission of the virus to a healthcare worker as the virus has passed on to many of them, however, it is very important to follow a basic protocol to protect them and prevent the transmission of the disease to them and others by them. Those who deal with patients directly are isolated from others and do not deal with ordinary patients. The rooms and surfaces and equipment should undergo regular decontamination. To reduce the spread of the disease in geographical areas, each country quarantines travelers and people who dealt with the injured for 14 days to ensure that they are free of the virus and prevent its spread. As for society, the best ways to prevent coronavirus and other viruses are necessary to move away from crowded places, leave a safe distance between others and follow a healthy lifestyle that is mainly based on maintaining personal hygiene, eating healthy foods, good ventilation, sunlight penetration on all surfaces, adequate rest, using health masks and using sterilizers on an ongoing every $15-20 \mathrm{~min}$. People who already have a vitamin C deficiency are more likely and at risk to become infected with the virus. So vitamin $C$ supplementation is very important for prevention according to many studies. ${ }^{[26-31]}$

Currently, no medication is proven to treat COVID-19 effectively, and no cure is available. Antibiotics aren't effective against viral infections such as COVID-19. The new coronavirus (COVID-19) is a virus and, therefore, antibiotics should not be used as a means of prevention or treatment. However, if the patient hospitalized for COVID19 he may receive antibiotics because bacterial co-infection is possible. There is no evidence that ibuprofen or other nonsteroidal anti-inflammatory drugs (NSAIDS) need to be avoided. Most patients have mild or no symptoms. However, mild cases are asymptomatic patients or patients with mild fever $37.5 \mathrm{C}^{\circ}$, cough, cold symptoms, nasal congestion, malaise, and without dyspnea, however, isolation of the patients is the most important care step for them and to others. The other approaches and strategies of the treatment depend upon the patient's situation and the symptoms. For example, if the patient has mild symptoms, it is recommended to stay at home for isolation of a period to avoid spreading the illness to others, as mentioned. If the patient is very ill, he may need to be treated in the hospital. Mild cases need supportive care and symptomatic treatment with antipyretic agents, if needed only, paracetamol is the first line and NSAIDs have caution in use, hydration and nutrition supplements should receive and ensure adequate calories intake. Frequent cough and fever monitoring. The organ function should routinely control, and any secondary infection should be prevented. All management is in their houses unless there are severe symptoms. If there is any development in the disease patient must refer to the healthcare center. ${ }^{[32,33]}$ Patients with confirmed COVID-19 disease and develop severe symptoms that have respiratory distress (less than $30 \mathrm{breath} / \mathrm{min}$ ), oxygen saturation less than $90 \%$, cyanosis, and shock must receive oxygen therapy by including nasal catheter and mask oxygenation and nasal high-flow oxygen therapy. If possible, inhalation of mixed hydrogen and oxygen $\left(\mathrm{H}_{2} / \mathrm{O} 2: 66.6 \% / 33.3 \%\right)$ can be applied to target more than $91 \%$ of oxygen saturation in nonpregnant adults and $92-95 \%$ to pregnant ones at room air. The nasal cannula is preferred for children with respiratory distress because it is better to tolerate. High flow nasal catheter or noninvasive mechanical ventilation is used when the respiratory distress does not relive after standard oxygen therapy. High flow nasal catheters consider safer than noninvasive ventilation because many scientists suggest that it may associate with the nosocomial transmission of the disease. About one third or two-third of critically ill-patients needs them. If the patient does not improve in time nearly $1-2 \mathrm{~h}$ invasive mechanical ventilation should be considered. The invasive mechanical ventilation used to avoid ventilator-induced lung injury while facilitating gas exchange via lung-protective ventilation. Patients with severe symptoms should be equipped with pulse oximeters, functioning oxygen systems and disposable, single-use, oxygen-delivering interfaces (nasal cannula, nasal prongs, simple face mask, and mask with reservoir bag), and should have regularly mentoring of the vital sign. In the case series of 99 hospitalized patients with COVID-19 infection from Wuhan, oxygen was given to $76 \%$, noninvasive ventilation in $13 \%$, mechanical ventilation in 4\%, ECMO in 3\%. Antiviral therapy consisting of oseltamivir, ganciclovir, and lopinavir-ritonavir was given to most patients (see later). ${ }^{[26,31,34]}$ Patients with severe COVID-19 develop a systemic inflammatory response that can lead to lung injury and multisystem organ dysfunction, it has been proposed and/ or given a potent anti-inflammatory (corticosteroids), which might prevent or mitigate these harmful effects (see later). In Palestine, the treatment and management protocols of COVID-19 are similar to the strategies and protocols in other countries, especially those 
who follow the guidelines of WHO. On March 26, 2020, the PA released the National COVID-19 Response Plan that outlined the strategic measures from several key sectors, including health, economy, and social protection to contain the outbreak. he $\mathrm{MoH}$ has implemented effective measures to ensure early detection and case management of any suspected COVID-19 case and so far have ensured that ${ }^{[4-6]}$ :

$\Delta$ In the West Bank, quarantine and treatment facilities and emergency committees were established in key governorates.

D MoH has developed a new COVID-19 dashboard (in Arabic) to track cases: https://www.corona.ps/.

A central operations room has been established at Prime Minister's office to coordinate activities, including contacts with media.

D Laboratory capacities of the MoH in Ramallah have been scaled up.

$\checkmark$ Point of entry checks for incoming travelers are being conducted and isolation wards in health facilities have been established.

D Health workers are equipped and trained in the appropriate infection prevention and control measures and case management of potential COVID-19 cases across the oPt.

D The general public continues to be regularly updated, including advice on how to protect themselves.

In the Gaza Strip, there are always substantial capacity gaps including the procurement of essential medical supplies and equipment (such as lab testing kits), This may be due to the siege, economic and political situations. The COVID-19 response plan for the oPt presented the joint strategy of the humanitarian community to respond to the public health needs and immediate humanitarian consequences of the pandemic. The main goal of the Plan was supporting the efforts led by the PA to contain the pandemic and mitigate its impact. PA from time to time updated their plan according to the outbreak of the disease and all the plans provided an important bridge between the public health response and the broader socio-economic recovery plan. The primary focus was prevention, preparedness, and treatment of COVID-19, with the emphasis remaining on supporting the most vulnerable people. According to PA officials, the interventions will continue to be adapted as the situation evolves and understanding of the virus and how it spreads. PA urged the public to obtain the latest information on COVID-19 from key and trustful sources such as $\mathrm{MoH}$ and WHO, and follow and promote the recommended basic preventive and protective measures. Overall, the plans supported scaling up the test capacity and expand hospitals' capacity. Respiratory supported and intensive care treatment capacity was also scaled-up. Additionally, the plans targeted citizens with public health messages on preventive measures on how to effectively protect oneself from COVID-19 infection, and health workers also supported with infection prevention and control (IPC) measures, including personal protective equipment (PPE) ${ }^{[4-6]}$ By June 2020, the $\mathrm{MoH}$ announced that Palestine entered a second wave of the coronavirus, and stressed the need for citizens to adhere to public safety measures, but pathologists and epidemiologists mentioned that was a continuation of the first wave and not considered a second wave, and it is obvious development after returning to normal life without taking any measures prevention and without commitment to instructions. The limitation of the disease outbreak at the beginning was due to the commitment by the citizens and the restricted follow-up by the government, so there were no infected cases recorded as this large number. But after the return to normal life without any regulation, it is natural for these cases to be recorded. Complete closure was at the beginning of the pandemic and by the end of May 2020, all facilities of life were comprehensively opened without any regulation. It seems to be that the secret to face this virus is regulation because closure is not a solution either, but the return of life to its nature must take place after taking measures. Thus, it was expected that a large number of cases will be recorded, because the number of contacts is large. $\mathrm{MoH}$ hoped that the increase would not be fast as in Hebron. The epidemiologists stressed that the citizens returned to normal life without taking the necessary measures such as masks, gloves, social distance, and sterilization, this gave chance for infected cases without any symptoms to transmit the virus, now the disease reached a stage that the source of the cases is unknown. Regarding the reasons for recording a large number of cases in Hebron, officials said it is obvious for this large number of cases to be recorded, as Hebron has a high population density (about a million) and it's close to the lands of the year 48 , in addition to a large number of patients and hospitals and health centers, who did not adhere to the necessary procedures and health safety regulations. ${ }^{[4-6]}$ Besides, the main reseason for the high outbreak of the disease in Hebron Governorate has been caused by people meeting up with their families or attending wedding parties or funerals and failing to follow health recommendations and maintain social distancing according to the Palestinian Ministry of Health (MoH) officials. The danger is not due to the unknown source of the infection, in the fact, anyone can be infected with the virus without he knows, so no precautions are taken because we and the patient do not know he is infected; although when we know someone is infected, we take the required precautions. However, if we do not know the source of the infection or infection, it 
would not be prevented. Also, other reasons which increased the cases were the analysis of the random samples that showed cases that unknow before. As the elimination of the virus depends on the vaccine, the best solution until that time, adherence to public safety measures such as social separation, sterilization, and the wearing of masks. Others mentioned also that the high recorded infected cases were expected because limiting movement during the emergency period reduced the spread of the virus and upon returning to normal life and mixing without any safety measures increased cases. If the closure lasts for a full year, infections will be recorded after returning to normal life. Therefore, until the vaccine is reached, which will not take place in a short time, all must adhere to public safety measures and social distance to limit the spread of the virus. The general director of preventive medicine at the $\mathrm{MoH}$ stressed the need to commit to the instructions and protocols issued by the $\mathrm{MoH}$ to all institutions, to be able to coexist with the virus, reduce transmission and spread of the epidemic, and curb the second wave of the pandemic, which is recorded in steady numbers. He said that the indicators showed that the situation is a candidate for increasing casualties and this was what he warned about it during the past period. According to the indications, the situation is expected to deteriorate further. He also announced what determines the coming measures are the epidemiological situation, therefore all scenarios are open according to data that changes rapidly, and he hoped not to reach to raise recommendations to restrict movement. But, by the beginning of July 2020, a total closure to West Bank was approved by the government according to the emergency, to end the outbreak of the coronavirus in its second wave, as hundreds of infections daily were recorded, the process was similar to that imposed at the beginning of the disease's arrival in March, which includes preventing the movement of the population and closing the economic and commercial sectors, except the necessary services. ${ }^{[4-6]}$ Hospitals and research labs all over the world are testing many different therapies on coronaviruspositive patients to find potential COVID-19 treatment. We highlight the medications, treatments, and management that have been applied to coronavirus. Table 2 summarizes the most important drugs used and/ or tested in treating COVID-19, including their rational use in the treatment of COVID-19, some other information was also included such as doses, methods of administration, and duration of treatment. ${ }^{[35-99]}$

In summary, patients with suspected or confirmed mild COVID-19 should be isolated to contain virus transmission according to the established COVID-19 care pathway. This can be done at a designated COVID-19 health facility, community facility, or at home (self-isolation). Patients with mild COVID-19 should be given symptomatic treatment such as antipyretics for fever and pain, adequate nutrition, and appropriate rehydration. Counsel patients with mild COVID-19 about signs and symptoms of complications that should prompt urgent care. Patients with suspected or confirmed moderate COVID-19 (pneumonia) should be also isolated to contain virus transmission. Patients with moderate illness may not require emergency interventions or hospitalization; however, isolation is necessary for all suspect or confirmed cases, and monitoring of signs or symptoms of disease progression for those patients is required. Severe patients should be equipped with pulse oximeters, functioning oxygen systems and disposable, single-use, oxygen-delivering interfaces (nasal cannula, Venturi mask, and mask with reservoir bag). Immediate administration of supplemental oxygen therapy to any patient with emergency signs and any patient without emergency signs and SpO $2<90 \%$; are recommended. Similar is recommended to those patients closely monitor for signs of clinical deterioration, such as rapidly progressive respiratory failure and shock, and respond immediately with supportive care interventions. Patients with COVID-19 and mild ARDS, a trial of HFNO, noninvasive ventilation continuous positive airway pressure (CPAP), bilevel positive airway pressure (BiPAP); may be used. Prompt recognition of progressive acute hypoxaemic respiratory failure when a patient with respiratory distress and is failing to respond to standard oxygen therapy and adequate preparation to provide advanced oxygen/ventilatory support and the endotracheal intubation is recommended. Patients with ARDS, especially young children or those who are obese or pregnant, may desaturate quickly during intubation, implementation of mechanical ventilation using lower tidal volumes $(4-8 \mathrm{~mL} / \mathrm{kg}$ predicted body weight $[\mathrm{PBW}])$ and lower inspiratory pressures (plateau pressure $<30 \mathrm{~cm}$ $\mathrm{H} 2 \mathrm{O}$ ) are recommended. In adult patients with severe ARDS $(\mathrm{PaO} 2 / \mathrm{FiO} 2<150)$, prone ventilation for $12-16$ hours per day is recommended. It is better to use a conservative fluid management strategy for ARDS patients without tissue hypoperfusion and fluid responsiveness. In patients with moderate or severe ARDS, a trial of higher positive end-expiratory pressure (PEEP) instead of lower PEEP is suggested and requires consideration of benefits versus risks. In COVID-19, we suggest the individualization of PEEP where during titration the patient is monitored for effects (beneficial or harmful) and driving pressure. In patients with moderate-severe ARDS $(\mathrm{PaO} 2 / \mathrm{FiO} 2<150)$; neuromuscular blockade by continuous infusion should not be routinely used. Disconnecting the patient from the ventilator, which results in loss of PEEP, atelectasis, and increased risk of 


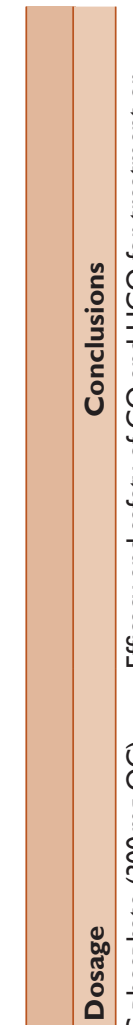

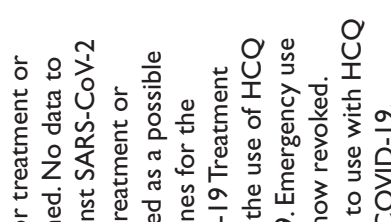

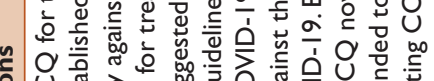

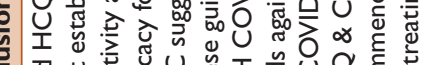

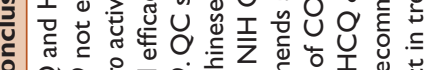

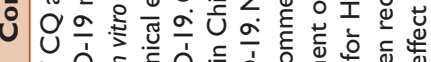

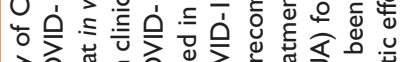

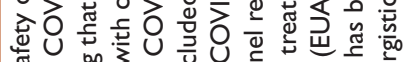

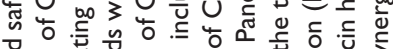
ट्र

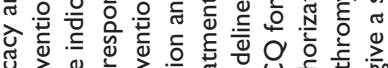

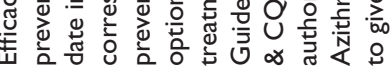

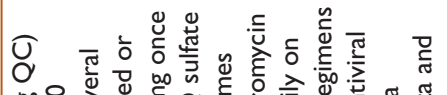

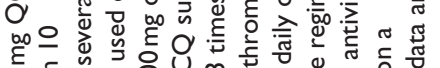

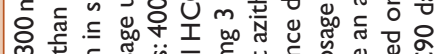

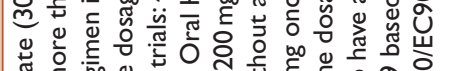

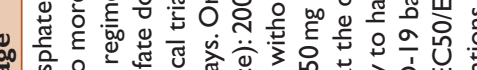

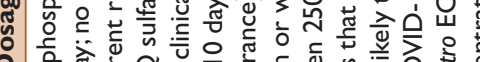

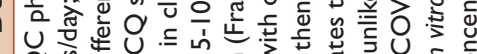
Ỡ प结

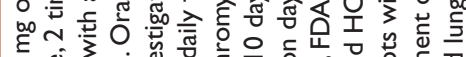

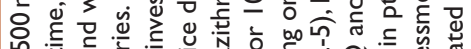

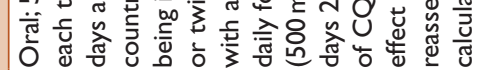

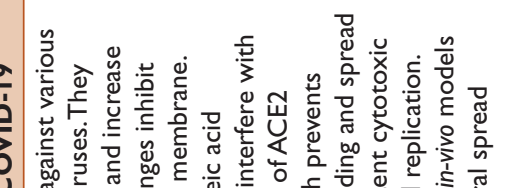

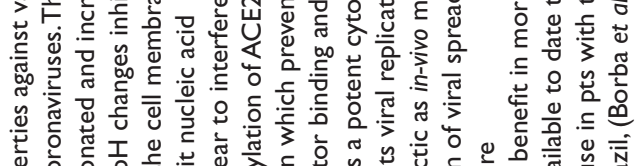
记 no

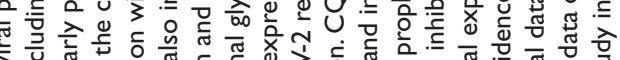

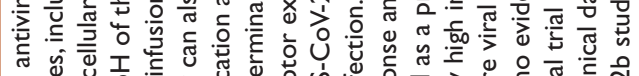
ब

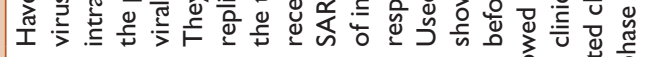

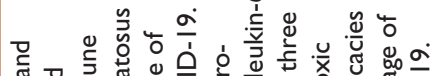

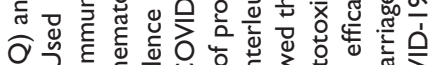

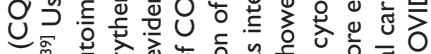

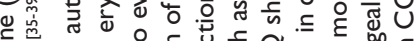

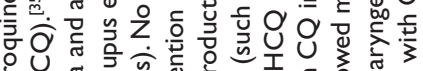

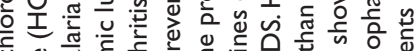
U.

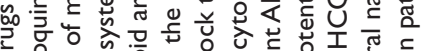
흔

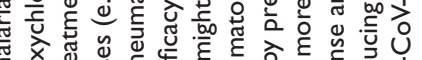

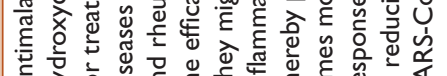

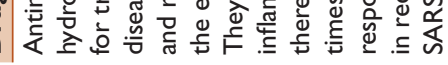

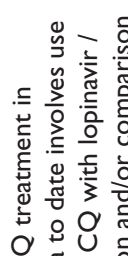

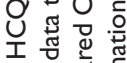

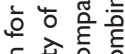

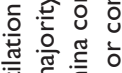

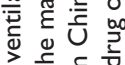

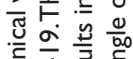

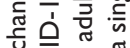

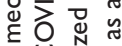

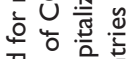

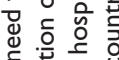

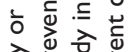

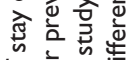

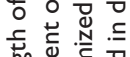

ฮै है 웜

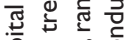

y 0 出

ডิ

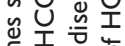

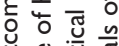

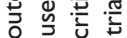

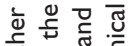

0 过

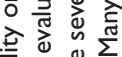

원 ठ

ㅇํㅁ

ปั่ อิ

过
ดั 흥

음 产造

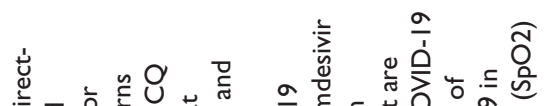

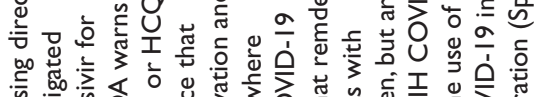

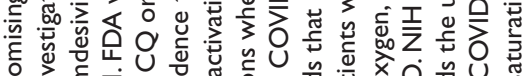

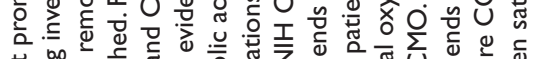

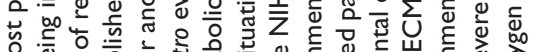

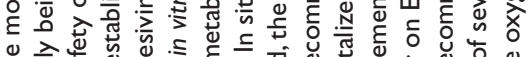

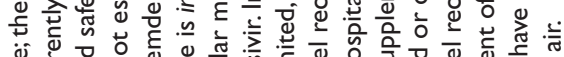

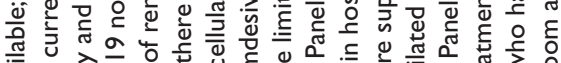

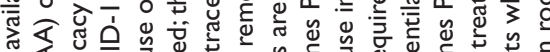

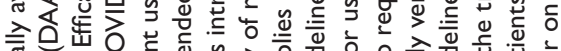

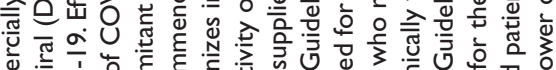

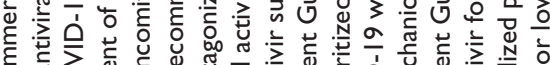
ठ

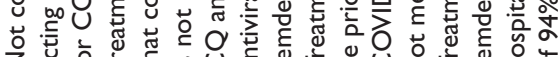

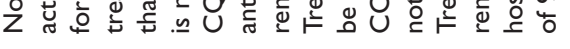

节

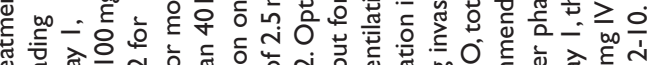

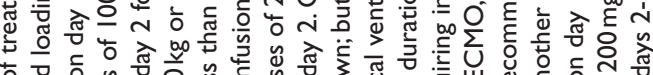
to

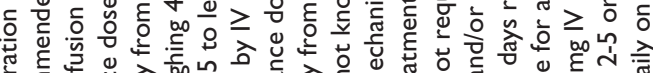

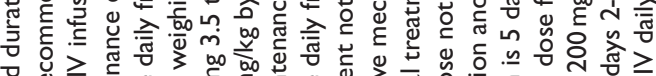

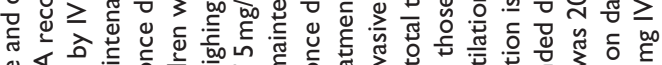

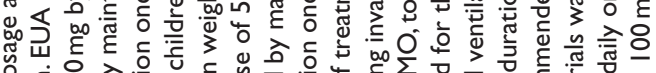

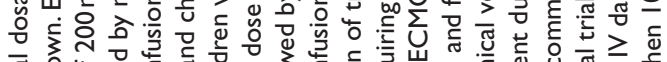

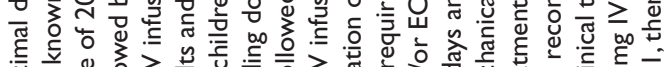

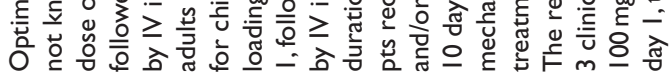

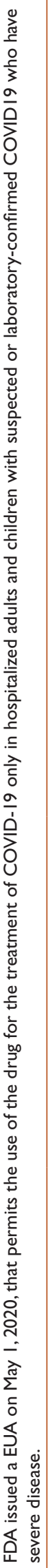

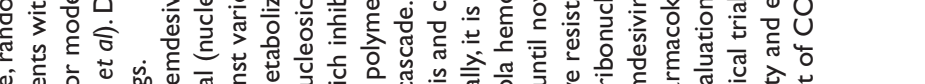

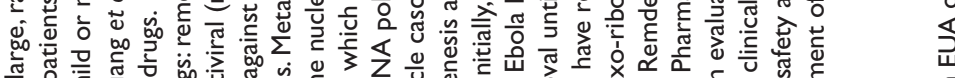

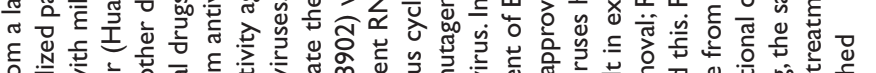

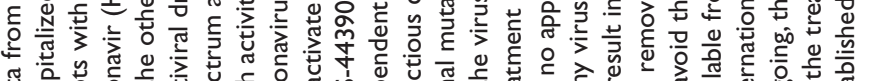

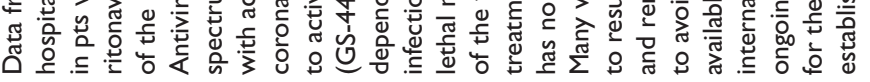

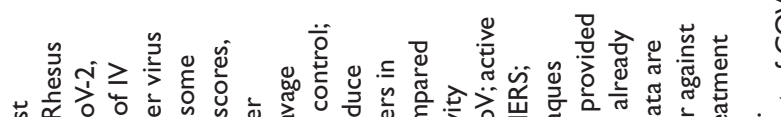

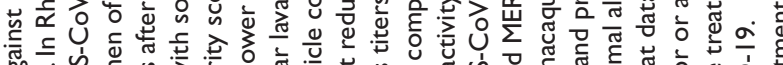

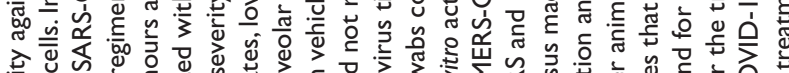

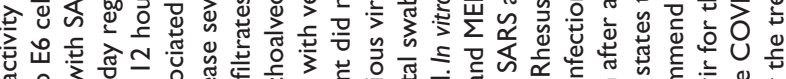

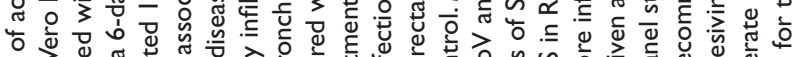
ป.

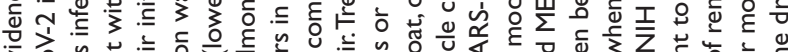
¿

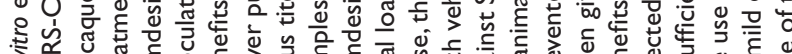

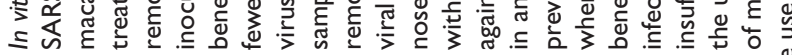

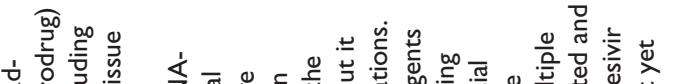

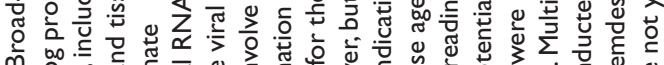

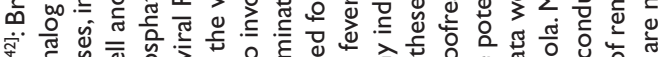

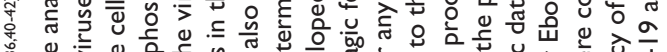

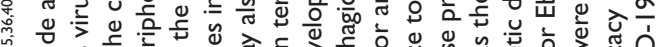

证

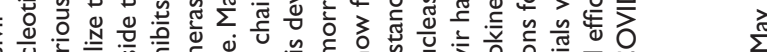

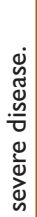



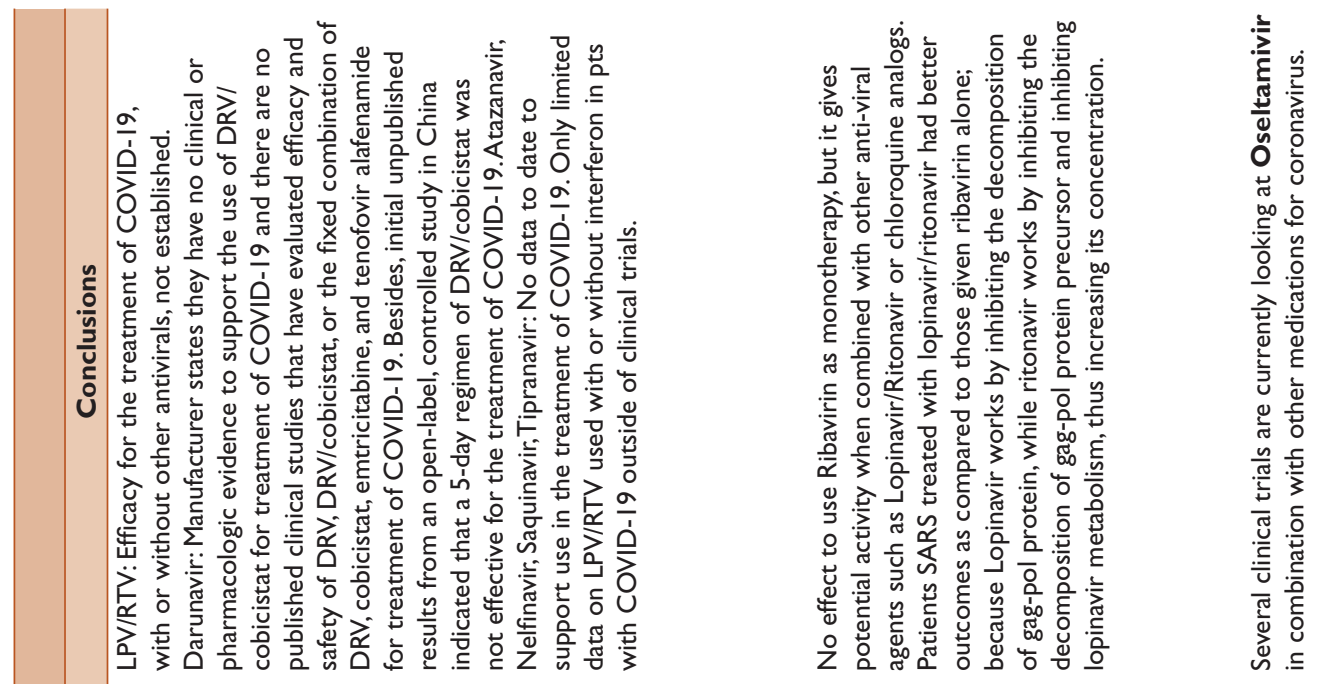

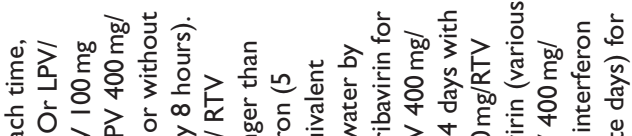

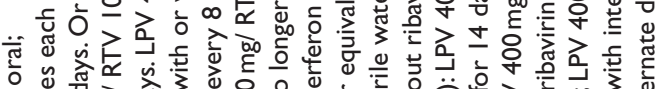

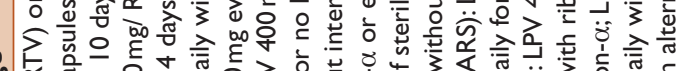

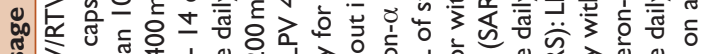

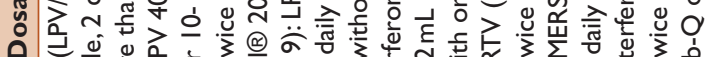

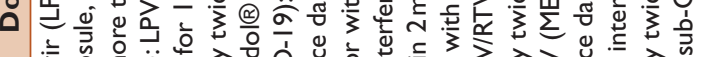

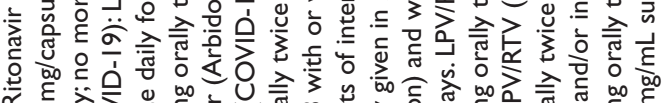

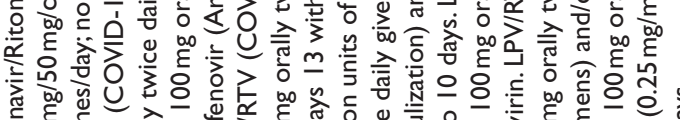

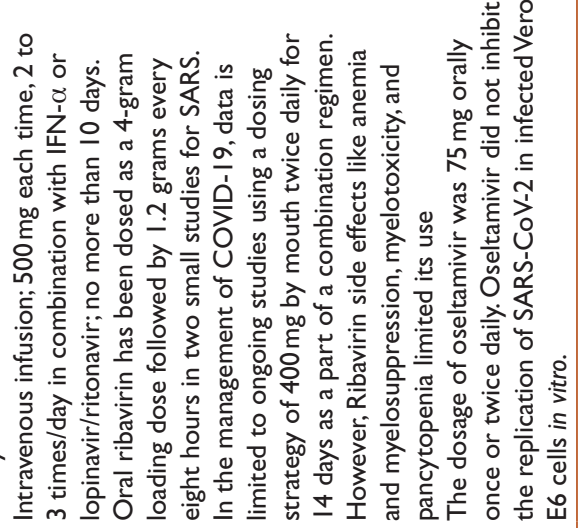

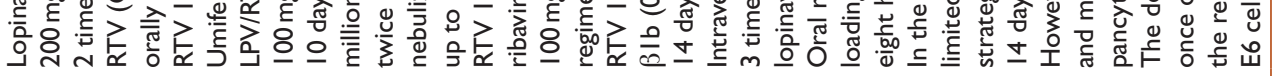

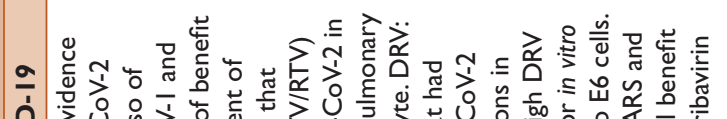

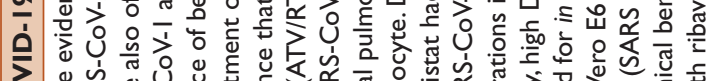

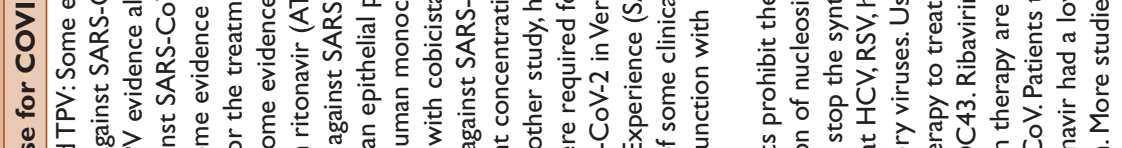

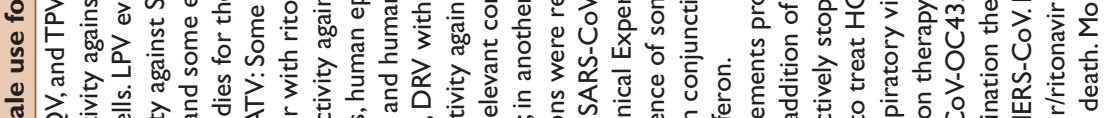

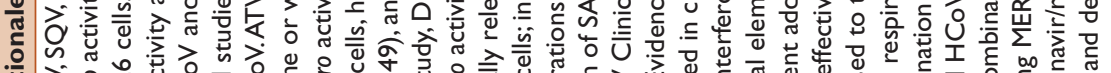

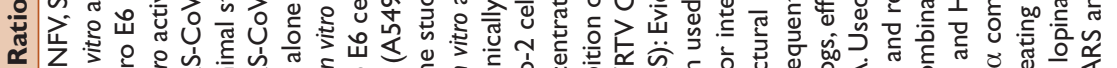

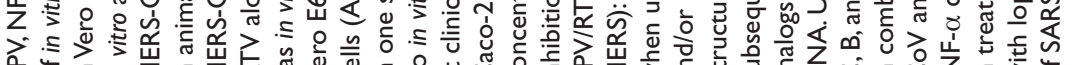

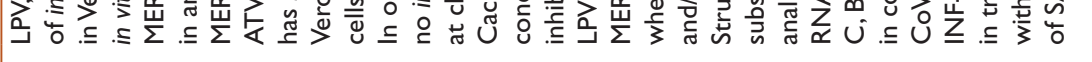

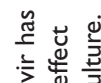

钧

긍

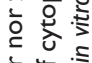

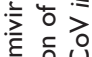

둰

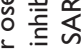

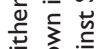

Zे

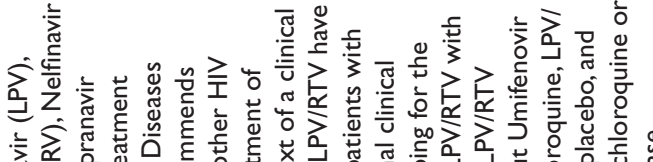

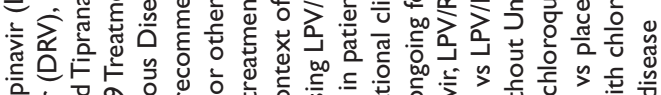

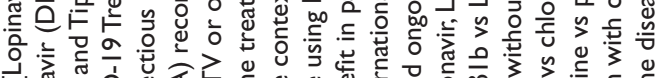

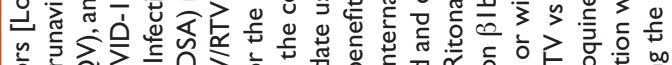

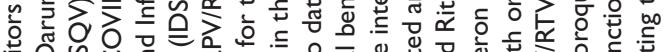

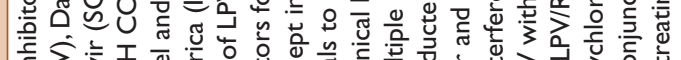

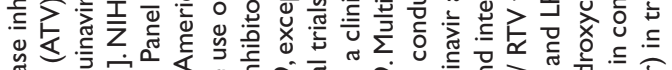

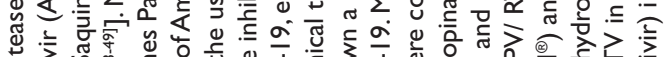

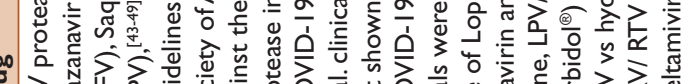

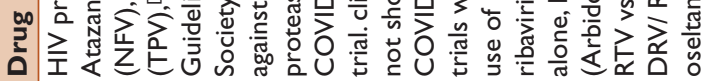

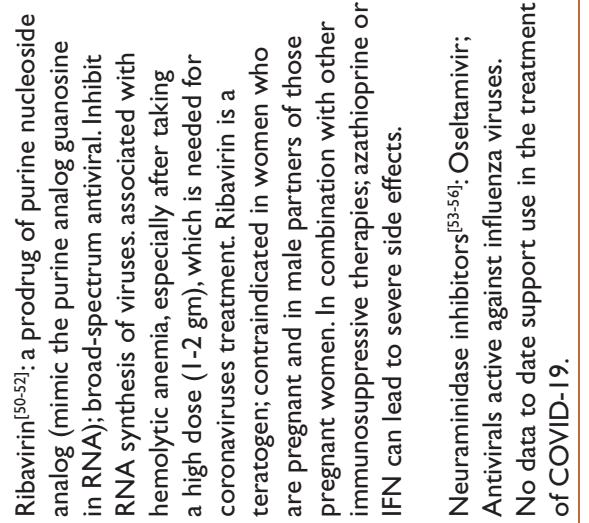



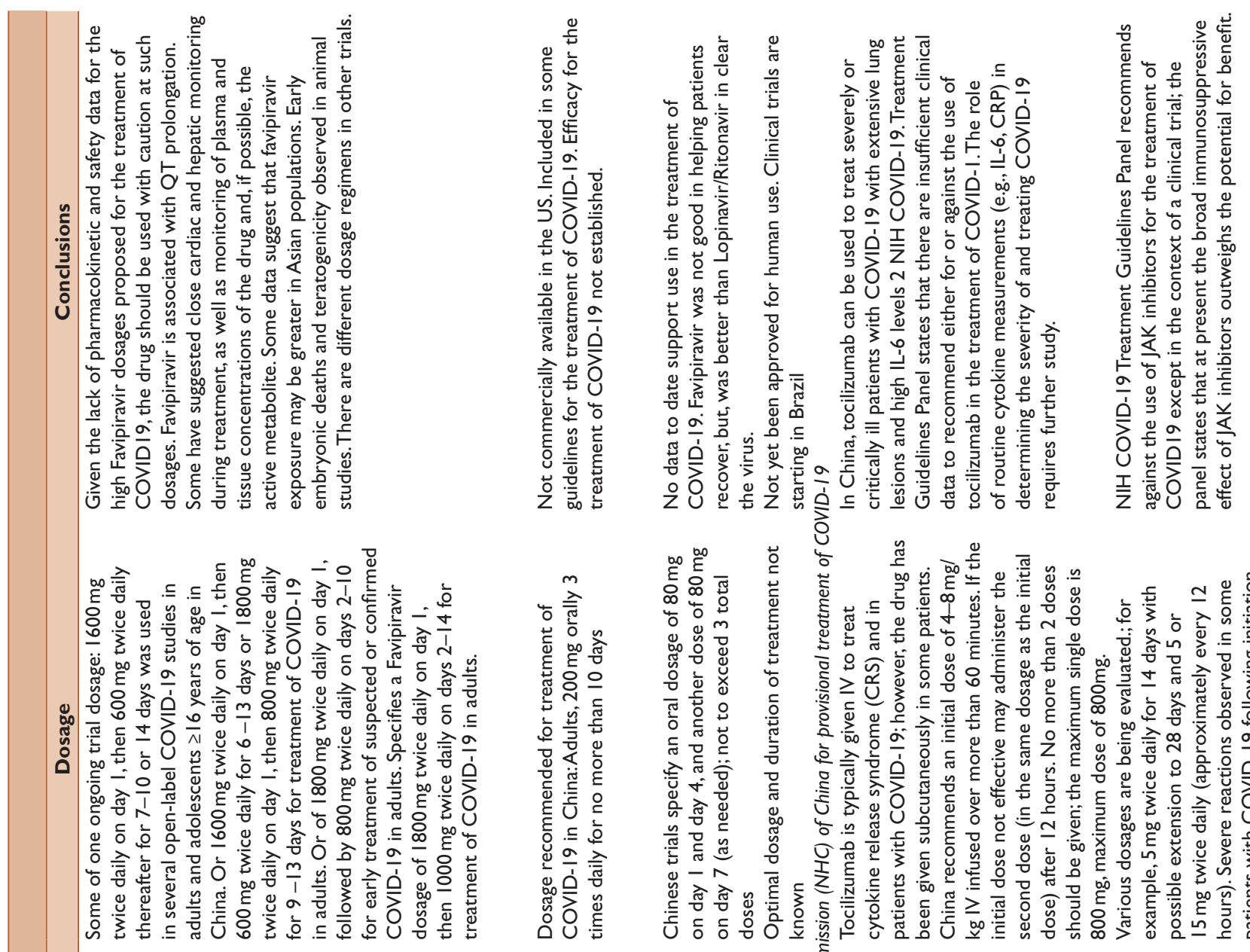

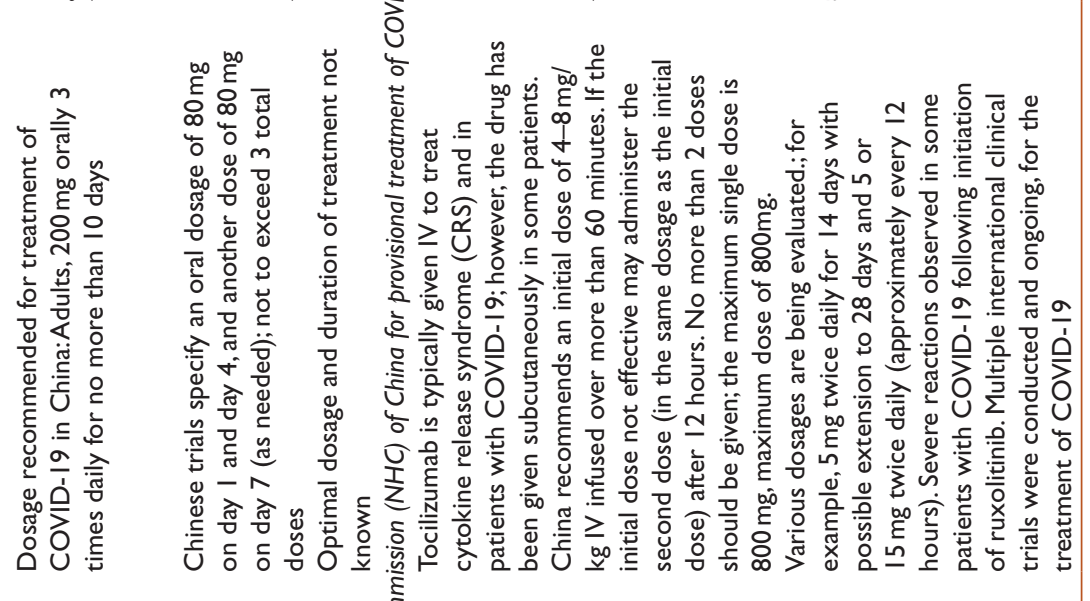
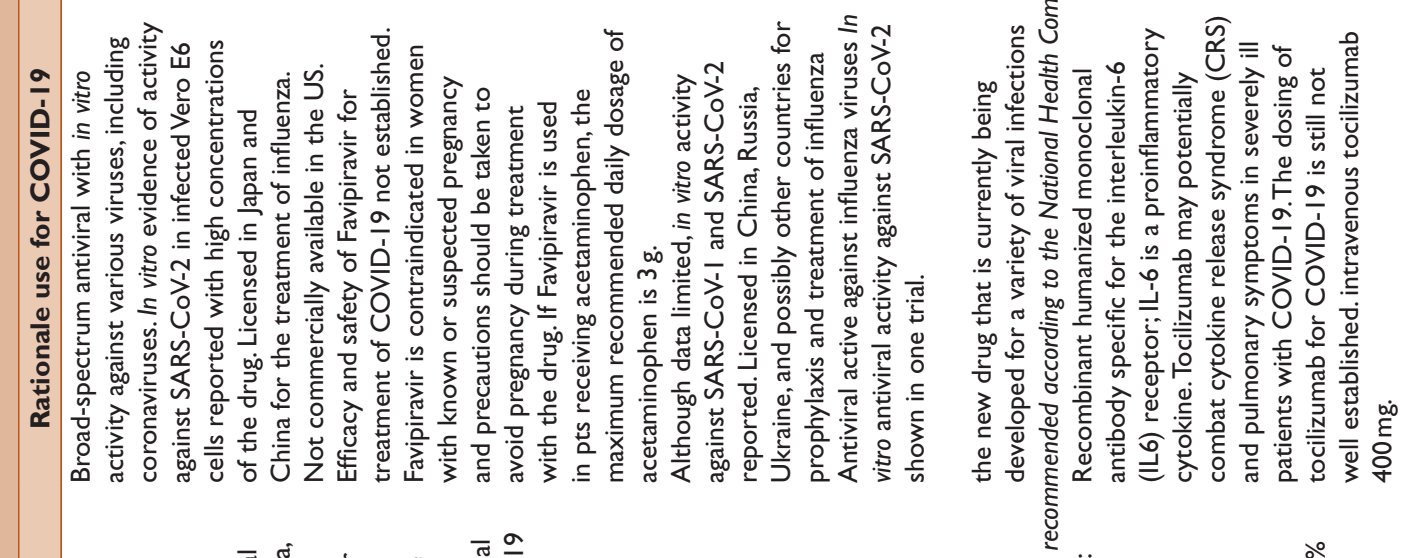

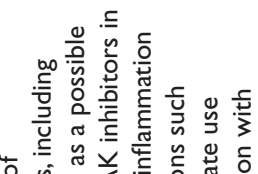

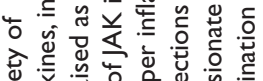

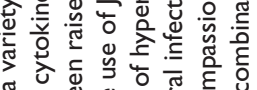

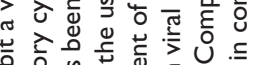

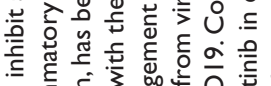

단,

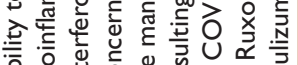

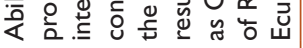

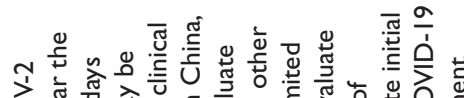

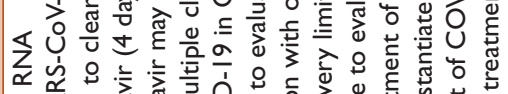

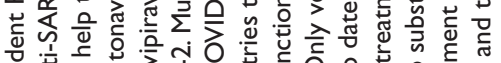

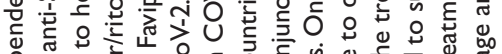

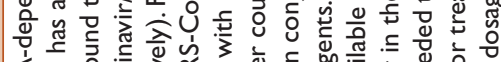

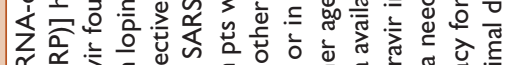

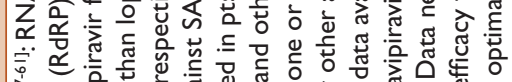

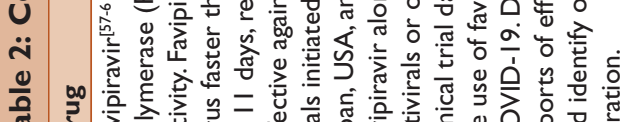
告

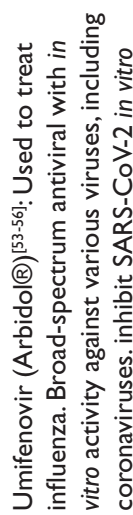

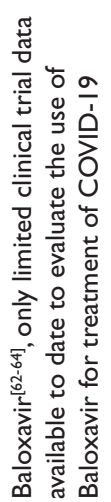

$$
\text { ข. }
$$

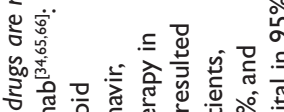

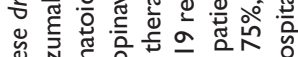

竞

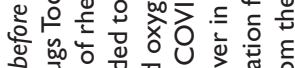

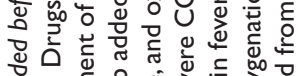

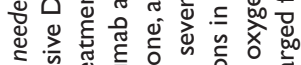

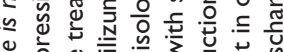

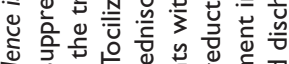

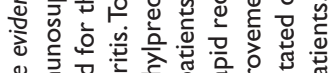

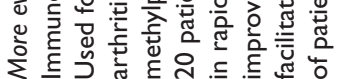

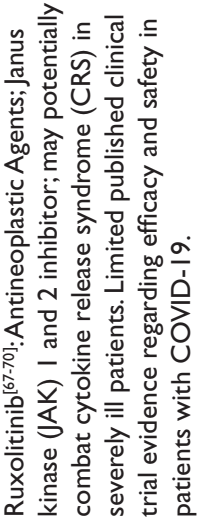




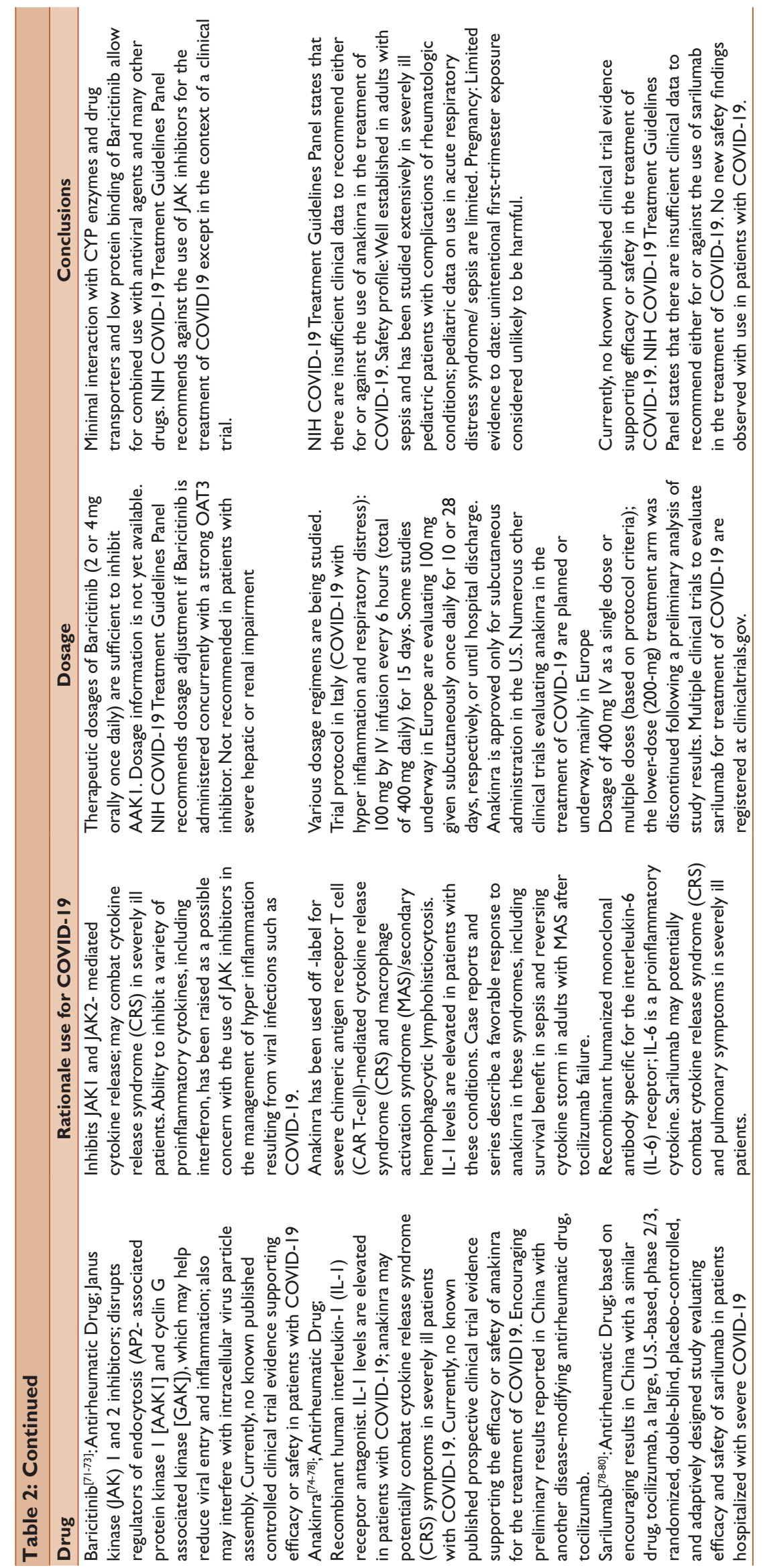




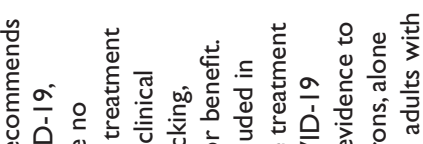

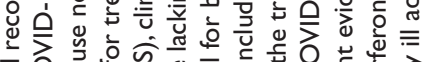

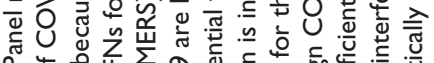

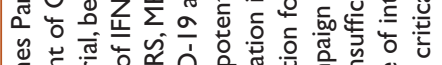

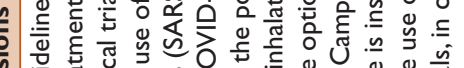

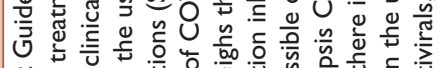

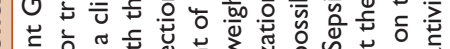

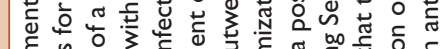

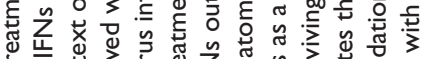

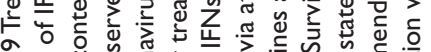
人 ठํ.

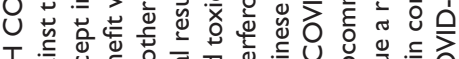

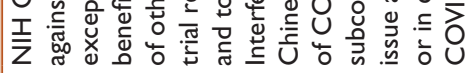

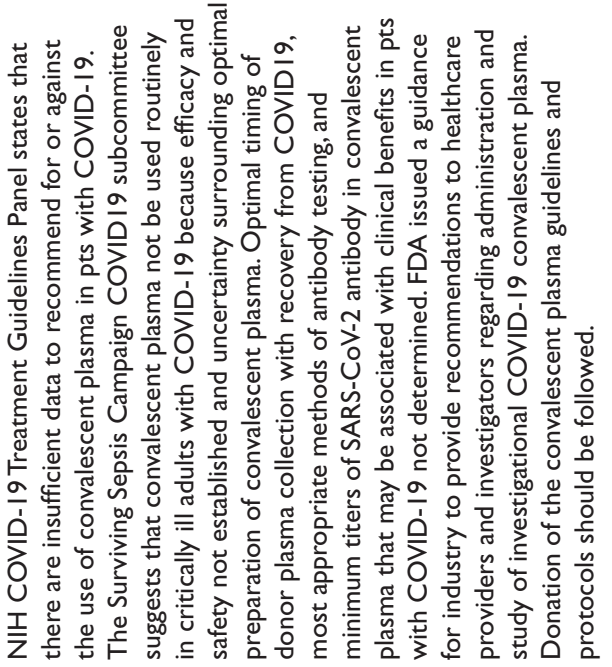

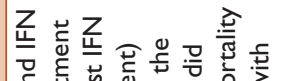

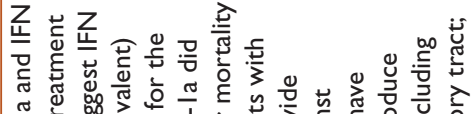

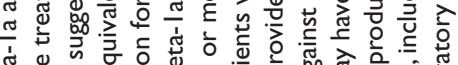

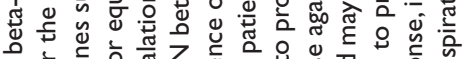

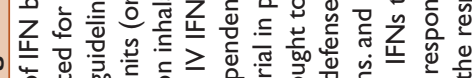
\%ั

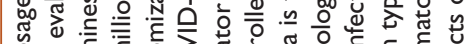
잉

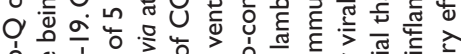

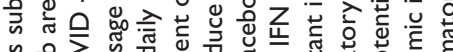

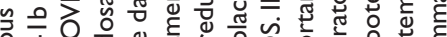

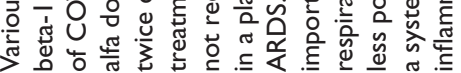

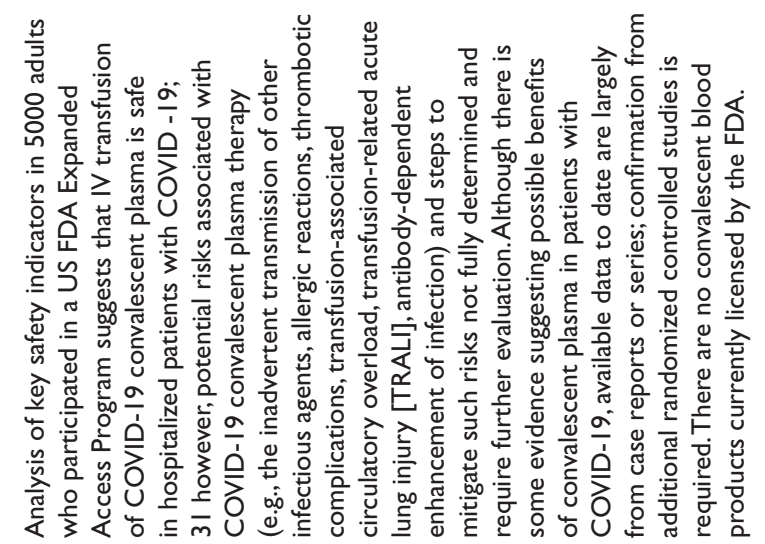

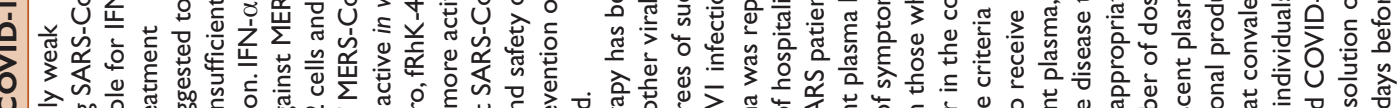

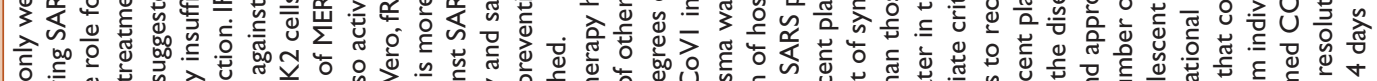

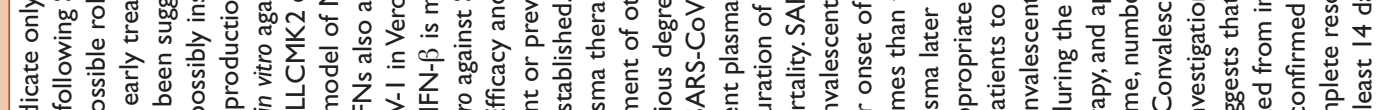

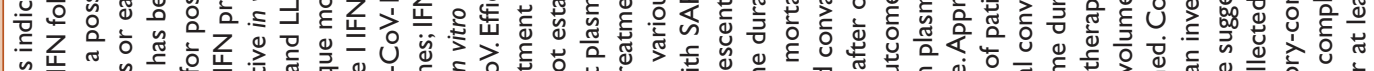

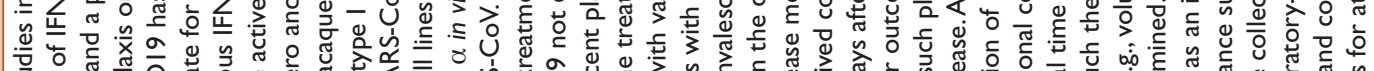

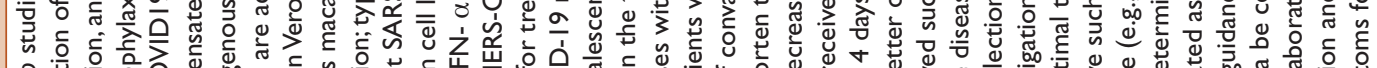

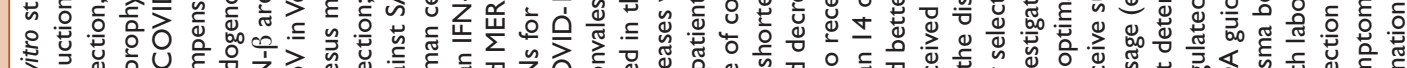

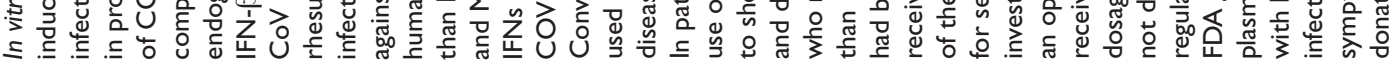

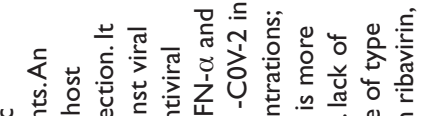

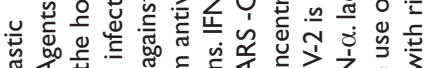

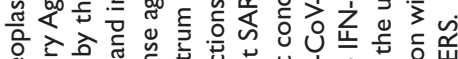

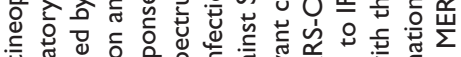

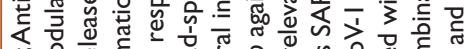
富 일

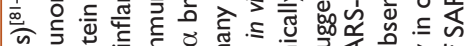

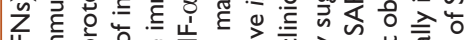

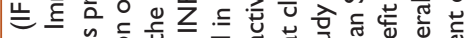

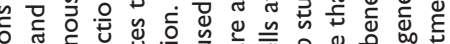

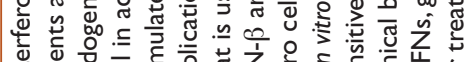

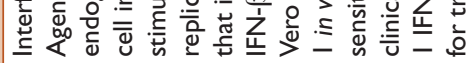

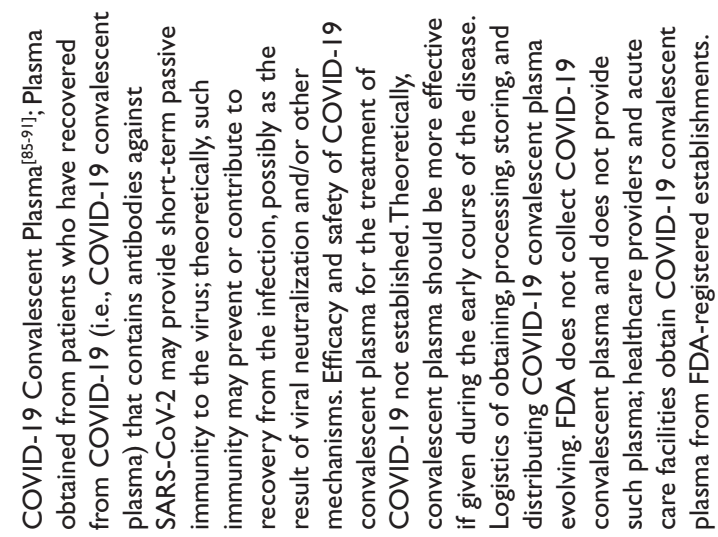




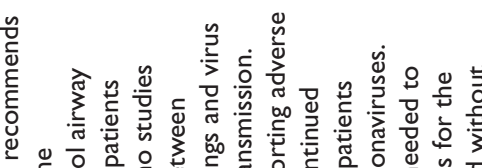

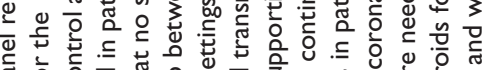

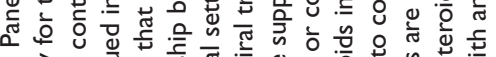

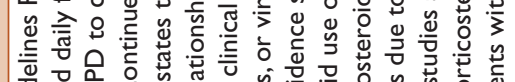

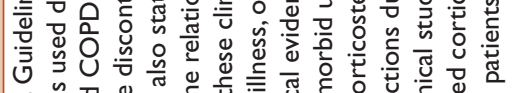

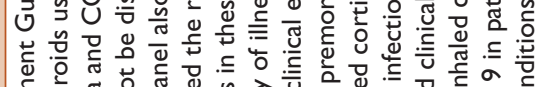

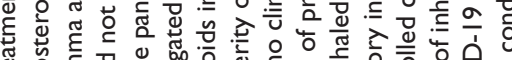

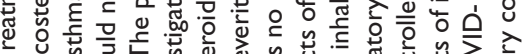

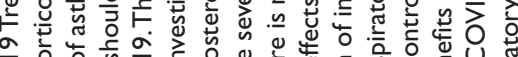

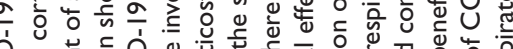

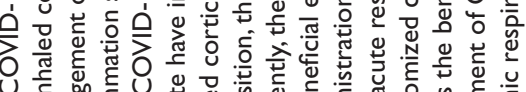

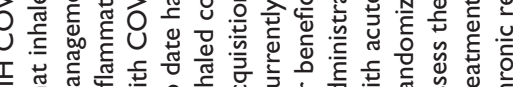

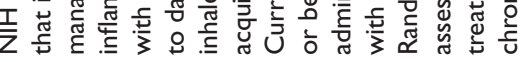

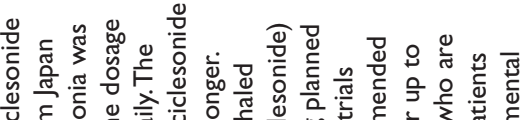

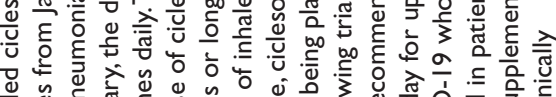

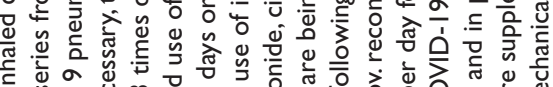

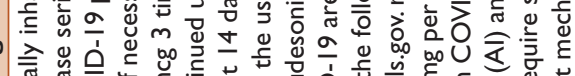

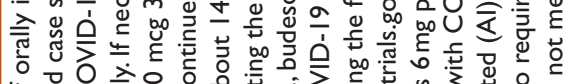

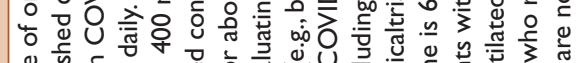

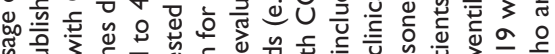

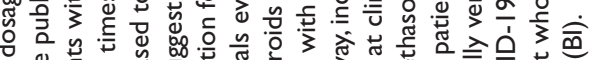

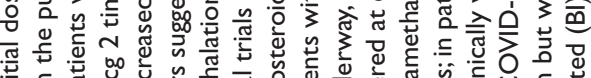

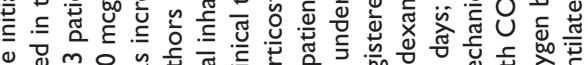

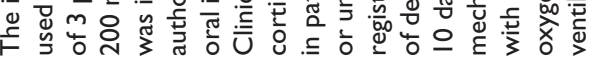

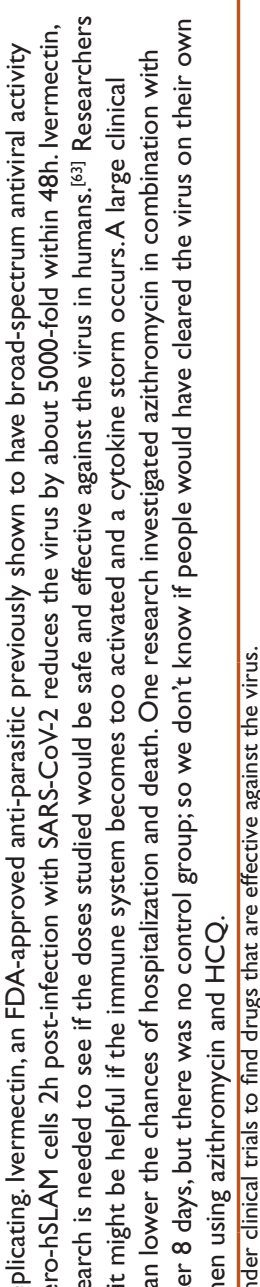

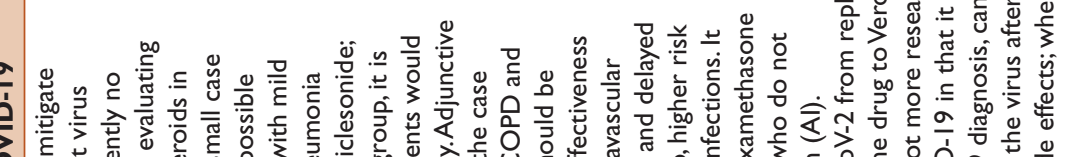

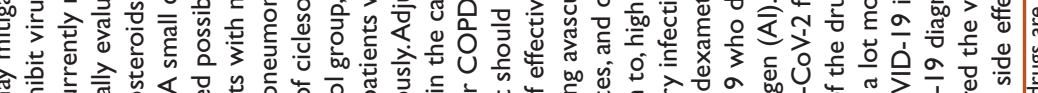

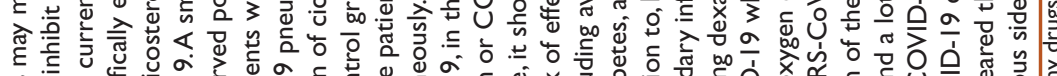

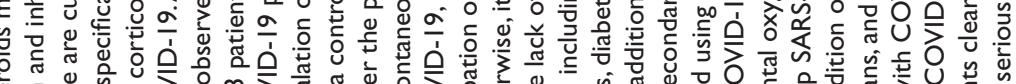

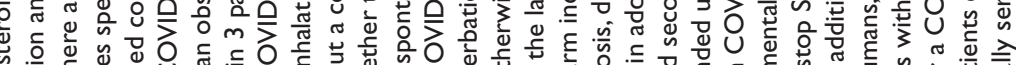

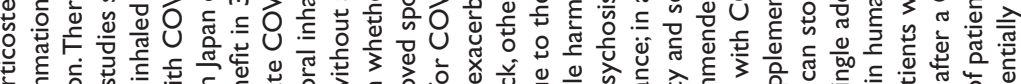

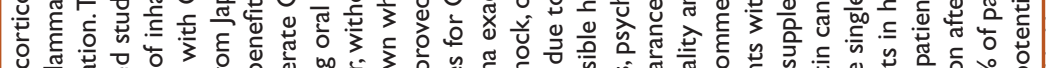

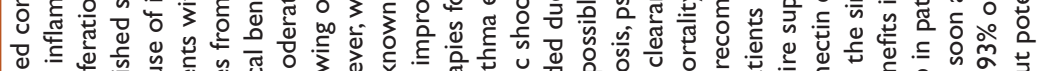

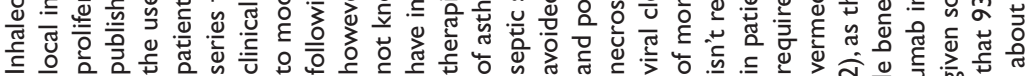

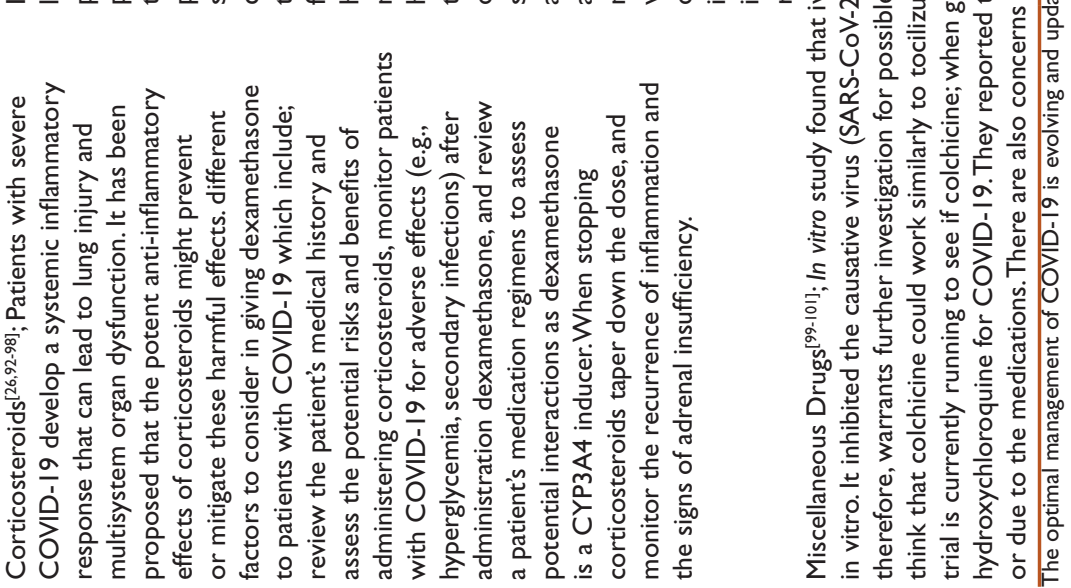


infection of health care workers is avoided. In patients with excessive secretions or difficulty clearing secretions, consider the application of airway clearance techniques. These should be performed only if deemed medically appropriate. Patients with ARDS in whom a lung-protective ventilation strategy fails; to achieve adequate oxygenation and ventilation, the ECMO is given. Recognize septic shock in adults when the infection is suspected or confirmed; vasopressors are needed to maintain mean arterial pressure (MAP) $\geq$ $65 \mathrm{mmHg}$ AND lactate is $\geq 2 \mathrm{mmol} / \mathrm{L}$, in the absence of hypovolaemia. Prevention of complications in hospitalized and critically ill patients with COVID-19; such as venous thromboembolism, low-molecular-weight heparin is used. For any other, clinically suspected; such as stroke, deep venous thrombosis, pulmonary embolism, or acute coronary syndrome, appropriate diagnostic and management pathways should proceed immediately. ${ }^{[78,81-85]}$ There are three broad approaches of drugs being investigated for the treatment of CPVID-19; which include: antiviral drugs; that directly affect the coronavirus's ability to thrive inside the body, immunotherapies; drugs that can calm the immune system; patients become seriously ill when their immune system overreacts and starts causing collateral damage to the body, and antibodies; either from survivors' blood or made in a lab, that can attack the virus. WHO recommended that several medicines shouldn't be administered or taken as prophylaxis for COVID-19. These drugs include; chloroquine and hydroxychloroquine (+/- azithromycin), antivirals, (Lopinavir/ritonavir, Remdesivir, Umifenovir, Favipiravir), immunomodulators (Tocilizumabm, Interferon- $\beta-1 \mathrm{a}$ ), and Plasma therapy. WHO also against the routine use of systemic corticosteroids for the treatment of viral pneumonia. For the treatment of other acute and chronic infections in patients with COVID-19; WHO also against the use of antibiotic therapy or prophylaxis in suspected or confirmed mild COVID-19. Besides, antibiotics should not be prescribed in suspected or confirmed moderate COVID-19; unless there is clinical suspicion of bacterial infection. In suspected or confirmed severe COVID-19, the use of empiric antimicrobials to treat all likely pathogens are based on clinical judgment, patient host factors, and local epidemiology; this should be done as soon as possible (within 1 hour of initial assessment if possible); ideally, after blood cultures obtained first. Antimicrobial therapy should be assessed daily for de-escalation. ${ }^{[27,102-106]}$ Caring for patients with suspected and confirmed COVID19; that have underlying noncommunicable diseases (NCDs); it is recommended to continue or modify their medicines; according to the patient's clinical condition. For example, antihypertensive drugs should not routinely be stopped in patients with COVID-19; but therapy may need to be adjusted; based on general considerations for patients with acute illness; with maintaining normal blood pressure and renal function. Careful consideration should be given to the numerous clinically significant side-effects of medications; that may be used in the context of COVID-19; as well as drug-drug interactions between medications; both of which may affect COVID-19 symptomatology (including effects on respiratory, cardiac, immune and mental and neurological function). Both pharmacokinetic and pharmacodynamic effects should be considered of the medications too. ${ }^{[102,107]}$ The antiviral drug Remdesivir gained an emergency use authorization from the FDA on May 1, 2020, based on preliminary data showing a faster time to recovery of hospitalized patients with severe disease. However, Remdesivir is considering the most promising antiviral drug. Also, other antiviral agents, immunotherapies, and vaccines continue to be investigated and developed as potential therapies for COVID-19. Numerous collaborative efforts to discover and evaluate the effectiveness of antivirals, immunotherapies, monoclonal antibodies, and vaccines have rapidly emerged.

\section{MANAGEMENT OF NEUROLOGICAL AND MENTAL MANIFESTATIONS ASSOCIATED WITH COVID-19}

COVID-19 is associated with mental and neurological manifestations, including delirium or encephalopathy, agitation, stroke, meningoencephalitis, impaired sense of smell or taste anxiety, depression, and sleep disorders. In many cases, neurological manifestations have been reported even without respiratory symptoms. Anxiety and depression appear to be common amongst people hospitalized for COVID-19; with one hospitalized cohort from Wuhan, China; revealing over $34 \%$ of people experiencing symptoms of anxiety and $28 \%$ experiencing symptoms of depression. Series cases in France found that $65 \%$ of people with COVID-19 in intensive care units (ICUs) showed signs of confusion (or delirium), and 69\% experienced agitation. Delirium, in particular, has been associated with increased mortality risk in the context of COVID-19. Moreover, there have been concerns related to acute cerebrovascular disease (including ischaemic and hemorrhagic stroke); in multiple case series from China, France, the Netherlands, and the United States of America. Case reports of Guillain-Barré syndrome and meningoencephalitis among people with COVID-19 have also been reported. It is recommended, in patients with COVID-19, that measures to prevent delirium, an acute neuropsychiatric emergency, be implemented; and patients be evaluated using standardized protocols, for the development of delirium. If detected, then immediate evaluation by a clinician is recommended to address any 
underlying cause of delirium and treat appropriately, and providing basic mental health and psychosocial support (MHPSS) for all persons with suspected or confirmed COVID-19. Promptidentification and assessment for anxiety and depressive symptoms in the context of COVID-19 should be considered; and to initiate psychosocial support strategies and first-line interventions, for the management of new anxiety and depressive symptoms. Psychosocial support strategies as the first-line interventions for the management of sleep problems in the context of acute stress also needed. ${ }^{[105]}$

\section{PREVENTIONS AND MANAGEMENT}

Evidence has shown that the groups of people most vulnerable to the development of severe illness due to the COVID-19 are the elderly, and those suffering from hypertension, pulmonary and cardiovascular diseases, cancer, and diabetes. COVID-19 affects the global population in drastic ways; older people face a greater risk of developing severe illness because of underlying health conditions and many physiological changes that come with age; which shall lead to declines in intrinsic capacity, manifested as the following malnutrition, cognitive decline, depressive symptoms, and potential underlying health conditions. Early detection of inappropriate medication prescriptions is recommended to prevent adverse effects of drug or potential drug interactions with COVID-19 treatment. Importantly, studies give proof that the transmission of this virus from human-to-human; along with many exported instances across the world. The geriatric population and people who are under some diseases are at risk of infection of this virus and susceptible to serious outcomes; which can be associated with acute breathing distress syndrome (ADRs). The are several limitations such as; the virus outbreaks very fast; thus the actual and accurate causes and effective treatment of COVID-19 are still unknown or unavailable, and the number of active cases of the infection is rising every day. However, the information about the disease including the number of cases and death are changing every day sharply worldwide. The global impact of this new pandemic is yet uncertain. The numbers are possibly an underestimate of the infected and dead due to limitations of surveillance and testing. As at this time there are no approved treatments for this infection, prevention is crucial and important. Several properties of this virus and/ or lack of precise information; make prevention is difficult; mainly; nonspecific features of the disease, the infectivity even before the onset of symptoms in the incubation period, transmission from asymptomatic people, long incubation period, tropism for mucosal surfaces such as the conjunctiva, prolonged duration of the illness and transmission even after clinical recovery. Isolation of confirmed or suspected cases with mild illness at home is recommended. The ventilation at home should be good with sunlight to allow for the destruction of the virus. Patients should be asked to wear a simple surgical mask and practice cough hygiene. Caregivers should be asked to wear a surgical mask when in the same room as the patient and use hand hygiene every $15-20$ minutes. ${ }^{[7,108]}$ The greatest risk in COVID-19 is transmission to healthcare workers. In the SARS outbreak of $2002,21 \%$ of those affected were healthcare workers. Almost more than 1500 healthcare workers in China have been infected with 6 deaths and about 600 US healthcare workers have died from COVID-19 (by the end of June). By May 6, the International Council of Nurses (ICN) reported that at least 90,000 healthcare workers had been infected and more than 260 nurses had died in the novel coronavirus pandemic. The physician in China; who first warned about the virus has died too. It is important to protect healthcare workers to ensure continuity of care and to prevent transmission of infection to other patients. Although COVID-19 transmits as a droplet pathogen and is placed in Category B of infectious agents (highly pathogenic H5N1 and SARS), by the China National Health Commission; infection control measures recommended are those for category A agents (cholera, plague). Patients should be placed in separate rooms or cohorted together. Negative pressure rooms are not generally needed. The rooms and surfaces and equipment should undergo regular decontamination preferably with sodium hypochlorite. Healthcare workers should be provided with fit-tested N95 respirators and protective suits and goggles. Airborne transmission precautions should be taken during aerosol-generating procedures such as intubation, suction, and tracheostomies. All contacts including healthcare workers should be monitored for the development of symptoms of COVID-19. Patients can be discharged from isolation once they are afebrile for at least 3 days and have two consecutive negative molecular tests at a 1-day sampling interval. This recommendation is different from pandemic flu where patients were asked to resume work/school once afebrile for $24 \mathrm{~h}$ or by day 7 of illness. Negative molecular tests were not a prerequisite for discharge. ${ }^{[7,108]}$

At the community level, people should be asked to avoid crowded areas and postpone nonessential travel to places with ongoing transmission. They should be asked to practice cough hygiene by coughing in sleeve/ tissue rather than hands and practice hand hygiene frequently every 15$20 \mathrm{~min}$. Patients with respiratory symptoms should be asked to use surgical masks. The use of a mask by healthy people in public places has not shown to protect against respiratory 
viral infections and is currently not recommended by WHO, but in most countries, they practice this. However, in China, the public has been asked to wear masks in public and especially in crowded places and large scale gatherings are prohibited (entertainment parks). China is also considering introducing legislation to prohibit the selling and trading of wild animals. The international response has been dramatic. Initially, there were massive travel restrictions to China, and people returning from China/ evacuated from China are being evaluated for clinical symptoms, isolated and tested for COVID-19 for 2 weeks even if asymptomatic. However, now with the rapid worldwide spread of the virus, these travel restrictions have extended to other countries. Whether these efforts will lead to the slowing of viral spread still uncertain. ${ }^{[72-75]}$ Healthcare providers should take travel history of all patients with respiratory symptoms, and any international travel in the past 2 weeks as well as contact with sick people who have traveled internationally. They should set up a system of triage of patients with respiratory illness in the outpatient department and give them a simple surgical mask to wear. They should use surgical masks themselves while examining such patients and practice hand hygiene frequently. Suspected cases should be referred to as government-designated centers for isolation. Patients admitted with severe pneumonia and acute respiratory distress syndrome should be evaluated for travel history and placed under contact and droplet isolation; regular decontamination of surfaces should be done. They should be tested for etiology using multiplex polymerase chain reaction (PCR) panels; if logistics permit and if no pathogen is identified, refer the samples for testing for SARS-CoV-2. All clinicians should keep themselves updated about recent developments including the global spread of the disease. International travel should be avoided and people should stop spreading myths and false information about the disease and try to allay panic and anxiety of the public. ${ }^{[27,108,110,111]}$ Physicians notice a septic shock in some adults when infected with COVID-19, the treatment goal is to maintain MAP $\geq$ $65 \mathrm{mmHg}$, lactate $\geq 2 \mathrm{mmol} / \mathrm{L}$. In absence of hypovolemia, the child will suffer from a septic shock with hypotension when (systolic blood pressure $[\mathrm{SBP}]<5$ th centile or $>2 \mathrm{SD}$ below normal for age) or suffers from two or more of the following: altered mental state; bradycardia or tachycardia ( $\mathrm{HR}<90 \mathrm{bpm}$ or $>160 \mathrm{bpm}$ in infants and $\mathrm{HR}<70 \mathrm{bpm}$ or $>150 \mathrm{bpm}$ in children); prolonged capillary refill $(>2 \mathrm{sec}$ ) or feeble pulses; tachypnea; mottled or cold skin or petechial or purpuric rash; increased lactate; oliguria; hyperthermia or hypothermia. When lactate measurement isn't available blood pressure (i.e., MAP) and clinical signs of perfusion can be used to define shock. ${ }^{[112]}$ Strategies for the resuscitation of adult and pediatric patients with septic shock include conservative fluid regimens, the crystalloid fluid which include normal saline and Ringer's lactate which is given as bolus infusion, hypotonic crystalloids, starches, or gelatins should not be used for resuscitation. Starches are associated with an increased risk of death and acute kidney injury. Gelatins are more expensive than crystalloids. Hypotonic solutions are less effective than isotonic at increasing intravascular volume. Treating Sepsis also suggests the use of albumin when patients require substantial amounts of crystalloids, but this recommendation is based on lowquality evidence. ${ }^{[113]}$ In adults with septic shock $250-500 \mathrm{~mL}$, the crystalloid fluid which includes normal saline and Ringer's lactate is given as rapid bolus in the first 15-30 minutes, in children $10-20 \mathrm{~mL} / \mathrm{kg}$ crystalloid fluid is given as a bolus in the first 30-60 minutes, check for signs of fluid overload after each bolus. Reduce or discontinue fluid administration; if there is evidence of no response by the patient to fluid loading; or if signs of volume overload appear on the patient (e.g., jugular venous distension, crackles on lung auscultation, pulmonary edema on imaging, or hepatomegaly in children); especially in patients with hypoxemic respiratory failure. Based on clinical response and improvement of perfusion targets additional fluid boluses may be given $(250-500 \mathrm{~mL}$ in adults or $10-20 \mathrm{~mL} / \mathrm{kg}$ in children). The Perfusion targets include MAP ( $>65 \mathrm{mmHg}$ or age-appropriate targets in children), urine output $(>0.5 \mathrm{~mL} /$ $\mathrm{kg} / \mathrm{hr}$ in adults, $1 \mathrm{~mL} / \mathrm{kg} / \mathrm{hr}$ in children), and improvement of skin mottling and extremity perfusion, capillary refill, heart rate, level of consciousness, and lactate. Notice indices for volume responsiveness to fluid administration; these indices include passive leg raises, fluid challenges with serial stroke volume measurements, or variations in systolic pressure, pulse pressure, inferior vena cava size, or stroke volume in response to changes in intrathoracic pressure during mechanical ventilation. In pregnant women with sepsis and or septic shock, they may need to be placed in the lateral decubitus position to off-load the inferior vena cava to reduce the hypotension. Management of septic shock in adults includes administration of vasopressors, in case if fluid administration does not restore adequate perfusion. In adults, norepinephrine is the first-line agent; epinephrine or vasopressin are preferred as the second line over dopamine.if patients didn't respond to usual doses of norepinephrine consider adding vasopressin rather than further titrating norepinephrine. In children, epinephrine is considered the first-line agent, and norepinephrine may be added if necessary. The initial blood pressure target is around $65 \mathrm{mmHg}$. If signs of septic shock persist despite administration of fluids and vasopressors; the patient shall be given an inotrope agent such as dobutamine rather than further titrating norepinephrine. ${ }^{[112-116]}$ 
In Palestine; the president of PA declared a state of emergency the same day that the first cases were identified (in Bethlehem) on 5 March 2020. In the beginning, Palestine was one of the lowest rates of virus spread and almost no community transmission, with 84 active cases in the West Bank and the Southern Governorates (Gaza Strip) reported (by March 25, 2020). As the COVID-19 incidence increases around the world, the PA continued efforts to contain the virus to protect the citizens and contributed to the global effort to end the pandemic. On March 22, the PA rolled out stricter suppression measures in the West Bank, preventing movement between governorates, closing all nonessential facilities, and asking the people in the West Bank to stay at home for 14 days. However, Palestine faces significant challenges in this effort, including a severely under-equipped health sector and an existing fiscal crisis caused by the Israeli authorities withholding of revenue. The COVID-19 and the emergency measures that the PA is taking are and will continue to have a significantly negative impact on the economics, which led to, shrinking revenues (by at least $40 \%$ ) that limit the ability to maintain the level of services and economic recovery. The approach of COVID-19 was to focuses on preparation, containment, and communication. The PA prepared an emergency response plan in late February and has worked with local and international partners to mobilize health professionals and facilities across the West Bank and equip them with training and the necessary protective gear, medical supplies, and medicine. Containing the virus outbreak was through testing and quarantining and restrictions on citizen movement. Individuals suspected to have COVID-19 are home quarantined until symptoms develop or they have a positive test. All in-coming travelers were placed in government quarantine for 2 weeks. Individuals with positive samples or symptoms are cared for in government hospitals. There are contact and trace units in each governorate. It was also launched a national coordinated communications campaign, passing public health and situation updates to citizens via national and local mechanisms on news, Facebook, and Twitter. The campaign includes a government COVID-19 tracking dashboard and collaboration with social media pages focused on tackling misinformation. The PA officials were twice-daily briefings through the national media, including updates on COVID-19 cases and government guidelines for citizens. The PA coordinated about COVID-19 with Jordan and Israeli authorities. Over weeks, the PA requested citizens comply with movement restrictions at the national and regional level, starting with the Bethlehem governorate, which had the first incidence of COVID-19. By 22 March, the following guidelines were taken ${ }^{[4-6]}$ : $\checkmark$ Closure of all schools, universities and public parks for 30 days (from 5 March - 5 April);

D Closure of all borders (movement of goods is allowed);

D Government quarantine (14 days) and testing for all incoming travelers (from Ben Gurion airport);

$\checkmark$ No movement between West Bank governorates;

D Palestinian laborers who travel to Israel for work are asked not to move between Palestine and Israel: this means that they should return to their homes (and remain in home quarantine for 2 weeks) or remain in Israel until the situation changes;

$\checkmark$ No movement within all urban areas (except for exceptional circumstances), with all citizens, requested to remain with their homes for 14 days (from March 22);

D Closure of all stores, public institutions, and government offices, except for essential providers (pharmacies and food) and the Ministries of Health, Finance and Interior (for 14 days from $22 \mathrm{March}$ );

DAll citizens are asked to stay at home, except for essential activities and emergencies (for 14 days from 22 March).

These actions were also extended and the Emergency across the oPt was declared up to 4 May. In this context, it has scaled up restrictions on movement between cities, commercial activities, and public gatherings, along with a suspension of all educational activities. On 20 April, a series of relaxation measures aimed at allowing the resumption of certain economies were announced. Palestinians entering the oPt from Jordan, Egypt and Israel have been ordered by the Palestinians authorities to stay in mandatory quarantine. Although in the Gaza Strip this measure has been strictly enforced, with all incoming people being referred to designated facilities, implementation in the West Bank has been partially due to its porous boundary with Israel, raising concern about a potential spread of the virus by workers that have been returned from Israel. ${ }^{[4-6,20]}$

\section{PALESTINIAN CHALLENGES}

The Challenges of PA in the fight to contain the COVID-19 outbreak was, Israeli military and economic control, no control over borders, national resources (medical and financial), many population high-risk characteristics of (crowded cities and refugee camps, poverty, food insecurity, and NCDs), and fiscal crisis. The budget deficit restricted the ability to cover operating expenses, pay salaries and pensions, and maintain the social safety network. In the context of COVID-19, PA is not able to cover the full salaries to employees including health workers. Additionally, there are insufficient funds to cover the scheduled government transfers to the most vulnerable population, with greater numbers of Palestinians expected to need government 
support due to the economic impact of COVID-19. The Gaza Strip is already in humanitarian and economic crisis. Thus, widespread incidence of the virus will be catastrophic in a population that is overcrowded, undersupplied, and in high poverty and food insecurity and ongoing closure of Gaza makes impossibility to freely mobilize the health resources if an outbreak of the disease. Across the oPt, the movement restrictions, closure of schools and growing unemployment is taking a toll on the most vulnerable. Service providers report that domestic violence affecting women and children is on the rise. Many families already live in poverty and the consequences of COVID-19 response measures have made it even harder for them to maintain their livelihoods and income. The Palestinian Ministry of Social Development (MoSD) estimates that at least 53,000 families across the oPt have fallen into poverty in recent weeks, due to the loss of a source of income. Without sufficient social protection and continuity of protection services for these vulnerable households, families risk plunging further into poverty and exacerbating already volatile family and community situations. The COVID-19 pandemic is characterized by the speed of its spread and difficulty to project how it will evolve at the country level. As a result, a mechanism to monitor the situation, needs and response are indispensable to rapidly adjust the interventions. The mandatory quarantine imposed by the PA to contain the virus, either home-based or at dedicated sites, has increased the risk of GBV including domestic violence affecting women and children, mental illness, and psychosocial deterioration. People with seeing, hearing, or mobility issues, already experience difficulty in accessing services and information in the oPt, now exacerbated as they seek to protect themselves from the outbreak. Many persons with disabilities depend on services that have been suspended and families report not having enough money to stockpile the specific food and medicine. Following the closure of education facilities in early March, 1.43 million children across the oPt need to continue distant learning and receive age-appropriate, awareness-raising messages around COVID-19. ${ }^{[4-6,20]}$ In Palestine, not only the elderly and people suffering from hypertension, pulmonary and cardiovascular diseases, cancer and diabetes are the most vulnerable to the development of severe illnesses due to the COVID-19 but, also there are several others people were impacted by the COVID-19 outbreak, which includes:

$\checkmark$ About 1,000 patients in Gaza cannot be referred to specialized treatment outside Gaza due to the crossing closure.

D More than 9,000 patients awaiting elective surgeries in Gaza (3,000 of which are urgent) that are postponed due to preparedness measures for the management of
COVID-19 cases. Similarly, in the West Bank, over 4,000 elective surgeries per month are postponed.

D About 50,000 individuals seeking outpatient support. Currently, there are over 50,000 outpatient appointments per month in the $\mathrm{MoH}$ and more than 2,000 referrals per month to non-MoH for outpatient appointments from the West Bank. Most are affected by movement restrictions and health service re-prioritization.

D Pregnant and lactating women and children who might not be able to receive essential healthcare because of health service re-prioritization.

D Palestinian refugees, wholive in one of the 19 overcrowded refugee camps, as well as Bedouin communities with inadequate living conditions most importantly, access to safe water and sanitation.

D Palestinians who are placed in quarantine facilities that may not be adequately prepared.

$\checkmark$ Children in detention are vulnerable to infection due to confinement, and at risk of neglect and abuse due to movement restrictions affecting the ability to access essential services.

As the COVID-19 pandemic spreads, concerns are particularly serious in conflict and humanitarian settings. Tackling the pandemic in those countries is challenging due to the fragility of socioeconomic and health systems. Palestine is one of those countries that is facing compounding challenges, instability, fragility, living conditions, poverty, and mobility, all of which are caused by multifactorial etiology. The Pandemic shows triple tragedies; virus (COVID-19 pandemic), ongoing Israeli control (Politics), and Intra-Palestinian divide (Policies). Yet, Palestine's response to the pandemic is outperforming many countries in the region. The early preventative lockdown measures in the West Bank found effective and not overwhelming the already overstretched health system. Although in the Gaza Strip the response was slow, prisoners, laborers, besieged people, socioeconomic-disadvantaged classes, and refugees were put at additional high risk. Nonetheless, measures taken were unconsolidated in both regions largely due to the political factors. A little collaboration and inter-agency task forces in preparedness and response were observed, and the mechanisms and governance remain ambiguous. A consolidated and evidence-based nation-wide plan is required, whereby state and nonstate actors have a clear and transparent exit strategy. A new thinking approach to promote the public health system and evidence-informed policies in Palestine is an urgent national priority ${ }^{[4-6,20]}$ Despite these measures, the capacity of the Palestinian health system to cope with a potential surge in the number of people suffering from serious symptoms due to COVID-19 is impaired by a range of factors. The situation is of particular concern 
in Gaza, where the health system has been undermined by the ongoing conflict between Hamas and Israel, the Israeli blockade, the internal Palestinian political divide, a chronic power deficit, and shortages in specialized staff, drugs, and equipment. In addition to capacity shortages, in the West Bank, vulnerable communities, particularly in Area C, continue to be affected by the Israeli authorities' destruction of property lacking building permits, as well as by Israeli settler violence, undermining their capacity to cope with the crisis. Several things should be emphasized which include; stope further transmission of COVID-19 across the oPt and reducing the demand for hospital critical care services and to avoid any overload of hospital care capacity, provide adequate care for patients affected by COVID-19 and to support their families and close contacts; and minimize the impact of the epidemic on the functional capability of the health system. Provide essential hygiene and disinfectant materials or cash for families and people at higher risk of being affected by COVID-19. Provide Non Food items (NFIs), such as bedding, cleaning, and hygiene materials to quarantine facilities. Improve hygiene conditions for families lacking basic facilities, such as latrines or kitchens, by providing appropriate hygiene materials, cleaning supplies, awareness materials, and technical consultancies and guidance. Contribute to mitigate the impacts of economic deterioration exacerbated as a result of the loss of income of the most vulnerable families by the provision of multipurpose cash or rental assistance. Distribute cleaning and hygiene packages to all schools in the $\mathrm{oPt}$ to prevent the spread of the pandemic before schools re-open. Rehabilitate the schools used as quarantine centers before re-open to ensure that they are back to normal status. Food support for most vulnerable households, including persons with disabilities, elderly and lactating and pregnant women, whose food security is directly affected by the virus outbreak. Clean and disinfected of all schools and public kindergartens in the oPt before re-opening. ${ }^{[4-6,20]}$

As there is currently no specific treatment for COVID-19, the most effective and impactful approach to protecting the population against the disease is containment measures, with a focus on early testing of all suspected cases, isolation and treatment of confirmed cases, contact tracing and quarantine arrangements, complemented by primary and community-based health initiatives with an emphasis on prevention and promotion of effective protection measures (hand hygiene and physical distancing). Efforts to scale up hospital preparedness and treatment capacity to manage an increase in demand for hospital-based patient care must continue. Strengthening the health care workforce and procurement of medicines, disposables, and equipment have been identified as the two crucial elements in fighting againstCOVID-19. The health workforce is the backbone of an effective health response and requires adequate technical support and protection. Therefore, it is important to mobilize further resources to provide adequate training health staff on most importantly clinical case management protocols and infection prevention and control policies. The unprecedented global demand for COVID-19 related materials, presents considerable challenges, particularly in the oPt. The approach, therefore, emphasizes a local procurement wherever possible, whilst maintaining quality control. The delays in global procurement serve to emphasize the need for a healthcare strategy that maximizes available resources and minimizes the consumption of currently limited materials. Therefore, PA recommended different strategies to be pursued which include; procurement and rational use of PPE, support quarantine facilities, enhance and rationalize laboratory testing, support case management of patients with COVID-19 who require hospital admission, enhance risk communication and community engagement and maintain core health services. As the COVID-19 continues to spread globally, vulnerable populations living in countries with weak health systems are at high risk of being hit the hardest. In conflict-torn countries and humanitarian settings, health and socioeconomic systems are already fragmented and overstretched to counter an outbreak. Furthermore, these settings suffer chronically from different forms of fragility, including weak health governance, high poverty and unemployment rates, high-density populations, and overcrowded refugee camps. They also suffer from poor access to essential WASH services, which are necessary for infection prevention and control. Health systems in these countries are ill-equipped and depleted by protracted conflicts and a large prevalence of co-morbidities such as NCDs according to WHO. All these factors increase the pandemics' transmissibility and high case-fatality and deter the COVID-19 preparedness and response modalities. The Middle East and North Africa (MENA) region is particularly experiencing multiple conflicts and political instabilities, which bring with them global health challenges. The impacts of devastating conflicts and political and social tensions in the region have been driving the emergence and spread of infections such as Cholera and COVID-19. The capacity to implement physical distancing and essential hygiene measures in conflict settings may prove unattainable. Humanitarian settings suffer from damaged health systems where they lack healthcare professionals, medicines, and equipment. Refugee camps and besieged areas also suffer from a lack of governance and access to essential needs and safe WASH services. The COVID-19 casualty and fatality rates are varied in the MENA region. According to 
the WHO, more cases have been reported in conflict-free countries with strong health systems (e.g., Qatar) compared to conflict-affected countries with poor health systems (e.g., Yemen). This is largely attributed to insufficient surveillance and testing capacity in conflict settings. On the other hand, fatality cases are relatively low in Turkey, Palestine, and Iran and high in Algeria and Egypt, when compared to the rest of the region's countries. Fatalities were high in countries that have a high percentage of elderly people in the population, large population density, and those with weak testing, diagnostic, and treatment capacities. Despite this, the region's governments have taken various and different degrees of containment measures to mitigate the COVID-19 spread. These include complete or partial lockdown of cities and different levels of physical distancing and hygiene promotion activities. Some in conflict countries have ceased fire and eased political tension in line with the current situation, yet the Israeli occupation multiplied attacks on Palestinians and aborted measures to curb the COVID-19 spread. This public health crisis reveals major gaps in the political and social systems of countries facing conflicts in the MENA region, where vulnerability, disparity, unpreparedness, distrust, and injustice are evident from the lack of strategic and comprehensive policies, resources misallocation, and lack of investment in public health priorities. Therefore, there are serious concerns about the current MENA region's capacity that needs an immediate real investment to halt the spread of this pandemic. A group of global public health scholars from the MENA region and local researchers from Palestine who specialized in health systems, health policies, and the burden of diseases led this policy analysis. We explored and analyzed the health system's response to the COVID-19 pandemic with a focus on Palestine, based on published data. We explored and reported some policy failures and successes related to the COVID-19 health system response and some of the recommend potential public health solutions and alternatives were also discussed. ${ }^{[4-6,20]}$ All infected patients should receive supportive care to help alleviate symptoms; and vital organ function should be supported in severe cases too as mentioned. In Palestine, the treatment and management protocols of COVID-19 are similar to the strategies and protocols in other countries especially those that follow the guidelines of WHO. The high outbreak of the disease in Hebron Governorate-Palestine has been caused by people meeting up with their families or attending wedding parties or funerals and failing to follow health recommendations and maintain social distancing according to the Palestinian $\mathrm{MoH}$ officials. However, isolation and other preventive and precautions are the most important ways in reducing the outbreak of the disease; which prevents the transmission of the virus to others. It is important to mobilize the community to combat rumors and misinformation. ${ }^{[4-6,20]}$

\section{CONCLUSION}

The $\mathrm{MoH}$ strategies to end the COVID-19 pandemic were; to stop the transmission of COVID-19 across oPt and reduce the demand for hospital critical care services and to avoid any overload of hospital care capacity; provide adequate care for patients affected by COVID-19 and to support their families and close contacts, and minimize the impact of the epidemic on the functional capability of the health system. The outbreak of the disease can be by applied health recommendations, isolation, and maintain social distance. PA strategies, guidelines, and protocols and plans against COVID-19 were similar to the other countries having the disease. But Palestine has different challenges and limitations in the treatment and management of the disease. The pandemic by COVID-19 is a very dangerous issue affecting people worldwide and still this pandemic is ongoing and no suitable treatments until now. Supportive treatment is still the main strategy in treating this disease; as no curative antiviral has been approved due to the lack of evidence and precise information. Isolating patients and other preventive and precautions are now the most important ways in reducing the outbreak of this virus; as these prevent the transmission of the virus to others or healthcare providers. However, there is an urgent need to develop targeted therapies. Understanding the disease and the different responses to this virus; could help to find immune-based therapeutics or/ and conventional medicines. It is important to have the latest information, but we must ensure that the information is coming from trustworthy sources. Thus, a variety of helpful resources related to COVID-19 treatments, management, and preventions have been collected. We explored and analyzed the health system's response to the COVID-19 pandemic including the challenges with a focus on Palestine.

Ethical policy and institutional review board statement

The identities of patients remained unknown and their identities remained confidential and only used for research purposes. The procedures were accomplished upon obtaining permission from the Ethical Committee of Hebron University.

Financial support and sponsorship Nil.

\section{Conflicts of interest}

There are no conflicts of interest. 


\section{REFERENCES}

1. World Health Organization. Coronavirus Disease (COVID-2019) Situation Reports. Available from: https:/www.who.int/emergencies/ diseases/novel-coronavirus-2019/situation-reports/. [Last accessed on 2020 Apr 9].

2. Centers for Disease Control and Prevention. Coronavirus Disease 2019 (COVID-19): Cases in U.S. 2020. Available from: https://www.cdc.gov/ coronavirus/2019-ncov/cases-updates/cases-in-us.html. [Last accessed on 2020 Apr 9].

3. Richman DD, Whitley RJ, Hayden FG. Clinical Virology. 4th ed. Washington, DC: ASM Press; 2016.

4. United Nations (UA). Occupied Palestinian Territory. COVID-19 Emergency Situation Report 6; 2020a. Available from: https:/www. ochaopt.org/content/covid-19-emergency-situation-report-6. [Last accessed on 2020 Apr 21-28].

5. United Nations (UA). Occupied Palestinian Territory. COVID-19 Emergency Situation Report 11; 2020b. Available from: https://www. ochaopt.org/content/covid-19-emergency-situation-report-11. [Last accessed on 2020 Jun 3-16].

6. United Nations (UN). The Question of Palestine. Coronavirus Disease 2019 (COVID-19) WHO Update 16; 2020c. Occupied Palestinian territory (epidemiological week 5). Available from: https://www.un.org/ unispal/document/coronavirus-disease-2019-covid-19-update-16/. [Last accessed on 2020 Mar 3].

7. Singhal T. A review of coronavirus disease-2019 (COVID-19). Indian J Pediatr 2020;87:281-6.

8. Guan WJ, Ni ZY, Hu Y, et al. Clinical characteristics of coronavirus disease 2019 in China. N Engl J Med 2020;382:1708-20.

9. Lauer SA, Grantz KH, Bi Q, Jones FK, Zheng Q, Meredith HR, et al. The incubation period of coronavirus disease 2019 (COVID-19) from publicly reported confirmed cases: Estimation and application. Ann Intern Med 2020;172:577-82.

10. Wu Z, McGoogan JM. Characteristics of and important lessons from the coronavirus disease 2019 (COVID-19) outbreak in China: Summary of a report of 72,314 cases From the Chinese Center for Disease Control and Prevention. JAMA2020. Available from: https://www.ncbi.nlm.nih. gov/pubmed/32091533.

11. Garg S, Kim L, Whitaker M, O'Halloran A, Cummings C, Holstein R, et al. Hospitalization rates and characteristics of patients hospitalized with laboratory-confirmed coronavirus disease 2019 - COVID-NET, 14 states, march 1-30, 2020. MMWR Morb Mortal Wkly Rep 2020;69:45 8-64.

12. Rothe C, Schunk M, Sothmann P, Bretzel G, Froeschl G, Wallrauch C, et al. Transmission of 2019-ncov infection from an asymptomatic contact in germany. N Engl J Med 2020;382:970-1.

13. Yu P, Zhu J, Zhang Z, Han Y, Huang L. A familial cluster of infection associated with the 2019 novel coronavirus indicating potential personto-person transmission during the incubation period. J Infect Dis 2020. Available from: https://www.ncbi.nlm.nih.gov/pubmed/32067043.

14. Bai Y, Yao L, Wei T, et al. Presumed asymptomatic carrier transmission of COVID-19. JAMA 2020. Available from: https:/www.ncbi.nlm.nih. gov/pubmed/32083643.

15. Wu C, Chen X, Cai Y, et al. Risk factors associated with acute respiratory distress syndrome and death in patients with coronavirus disease 2019 pneumonia in Wuhan, China. JAMA Intern Med 2020. Available from: https://www.ncbi.nlm.nih.gov/pubmed/32167524.

16. Cai Q, Chen F, Luo F, et al. Obesity and COVID-19 severity in a designated hospital in Shenzhen, China. Lancet 2020. Available from: https:// papers.ssrn.com/sol3/papers.cfm?abstract_id $=3556658$.

17. Centers for Disease Control and Prevention. Coronavirus Disease 2019 (COVID-19): People Who Are at Higher Risk for Severe Illness. 2020. Available from: https://www.cdc.gov/coronavirus/2019-ncov/need-extraprecautions/people-at-higher-risk.html [Last accessed on 2020 Apr 8].
18. Shi $\mathrm{H}, \mathrm{Han} \mathrm{X}$, Jiang $\mathrm{N}$, et al. Radiological findings from 81 patients with COVID-19 pneumonia in Wuhan, China: A descriptive study. Lancet Infect Dis 2020;20:425-34.

19. Hellewell J, Abbott S, Gimma A, Bosse NI, Jarvis CI, Russell TW, et al.; Centre for the Mathematical Modelling of Infectious Diseases COVID-19 Working Group. Feasibility of controlling COVID-19 outbreaks by isolation of cases and contacts. Lancet Glob Health 2020;8:e488-96.

20. AlKhaldi M, Kaloti R, Shella D, Al Basuoni A, Meghari H. Health system's response to the COVID-19 pandemic in conflict settings: Policy reflections from Palestine. Int J Res Policy Pract 2020;15:1244-56.

21. Wu A, Peng Y, Huang B, Ding X, Wang X, Niu P, et al. Genome composition and divergence of the novel coronavirus (2019-ncov) originating in china. Cell Host Microbe 2020;27:325-8.

22. Wu J, Liu J, Zhao X, Liu C, Wang W, Wang D, et al. Clinical characteristics of imported cases of covid-19 in Jiangsu province: A multicenter descriptive study. Clin Infect Dis 2020.

23. Wu Z, Mcgoogan JM. Characteristics of and important lessons from the coronavirus disease 2019 (COVID-19) outbreak in China: Summary of a report of 72314 cases from the Chinese Center for Disease Control and Prevention. JAMA 2020;323:1239-42.

24. WHO 2020a. Clinical Management of Severe Acute Respiratory Infection when Novel Coronavirus ( $\mathrm{nCoV}$ ) Infection is Suspected. Interim guidance. Published on January 28, 2020.

25. Alhazzani W, Alshamsi F, Belley-Cote E, Heels-Ansdell D, BrignardelloPetersen R, Alquraini M, et al. Efficacy and safety of stress ulcer prophylaxis in critically ill patients: A network meta-analysis of randomized trials. Intensive Care Med 2018;44:1-11.

26. Russell CD, Millar JE, Baillie JK. Clinical evidence does not support corticosteroid treatment for 2019-ncov lung injury. Lancet 2020;395:473-5.

27. Yoshikawa TT, High K. Nutritional strategies to boost immunity and prevent infection in elderly individuals. Clin Infect Dis 2001;33:1892900.

28. Nonnecke BJ, McGill JL, Ridpath JF, Sacco RE, Lippolis JD, Reinhardt TA. Acute phase response elicited by experimental bovine diarrhea virus (BVDV) infection is associated with decreased vitamin $\mathrm{D}$ and $\mathrm{E}$ status of vitamin-replete preruminant calves. J Dairy Sci 2014;97:5566-79.

29. Sara Reardon. Antibiotic treatment for COVID-19 complications could fuel resistant bacteria. Science's COVID-19 reporting is supported by the Pulitzer Center. Health Coronavirus. doi:10.1126/science.abc2995

30. Zhang L, L Y. "Potential interventions for novel coronavirus in China: A systemic review." J Med Virol 2020;92:479-90.

31. Xu XW, X W, Jiang XG, et al. "Clinical findings in a group of patients infected with the 2019 novel coronavirus (SARS-Cov-2) outside of Wuhan, China: Retrospective case series. BMJ 2020;368:m606.

32. Zhang $\mathrm{W}$, et al. The use of anti-inflammatory drugs in the treatment of people with severe coronavirus disease 2019 (COVID-19): The Perspectives of clinical immunologists from China. Clin Immunol 2020;214:108393.

33. Jin YH, C. L., Cheng ZS, et al. "A rapid advice guideline for the diagnosis and treatment of 2019 novel coronavirus [2019-nCoV] infected pneumonia”. Mil Med Res 2020;7:4.

34. Li G, Chen X, Xu A. Profile of specific antibodies to the SARS-associated coronavirus. N Engl J Med 2003;349:508-9.

35. Wang M, Cao R, Zhang L, Yang X, Liu J, Xu M, et al. Remdesivir and chloroquine effectively inhibit the recently emerged novel coronavirus (2019-ncov) in vitro. Cell Res 2020;30:269-71.

36. Devaux CA, Rolain JM, Colson P, Raoult D. New insights on the antiviral effects of chloroquine against coronavirus: What to expect for COVID-19? Int J Antimicrob Agents 2020;55:105938.

37. Cortegiani A, Ippolito M, Ingoglia G, Iozzo P, Giarratano A, Einav S. Update I. A systematic review on the efficacy and safety of chloroquine/hydroxychloroquine for COVID-19. J Crit Care 2020;59: 176-90. 
38. US Food and Drug Administration. Letter of Authorization: Emergency Use Authorization for Use of Chloroquine Phosphate or Hydroxychloroquine Sulfate Supplied from the Strategic National Stockpile for Treatment of 2019 Coronavirus Disease. 2020 Mar 28. Available from: https://www.fda.gov/media/136534/download.

39. Sahraei Z, Shabani M, Shokouhi S, Saffaei A. Aminoquinolines against coronavirus disease 2019 (COVID-19): Chloroquine or hydroxychloroquine. Int J Antimicrob Agents 2020;55:105945.

40. National Institutes of Health. Coronavirus Disease 2019 (COVID-19) Treatment Guidelines. Updated 2020 Jul 17. Available from: https:// www.covid19treatmentguidelines.nih.gov/. [Last accessed on 2020 Jul 21].

41. Williamson BN, Feldmann F, Schwarz B, et al. Clinical benefit of remdesivir in rhesus macaques infected with SARS-CoV-2. Nature 2020 Jun 9 [Epub ahead of print]. PMID: 32516797. doi: 10.1038/s41586020-2423-5.

42. Gilead Sciences. Emergency Access to Remdesivir Outside of Clinical Trials. Available from: https:/www.gilead.com/purpose/advancingglobal-health/covid-19/emergency-access-to-remdesivir-outside-ofclinical-trials. [Last accessed on 2020 May 24].

43. Sheahan TP, Sims AC, Leist SR, Schäfer A, Won J, Brown AJ, et al. Comparative therapeutic efficacy of remdesivir and combination lopinavir, ritonavir, and interferon beta against MERS-cov. Nat Commun 2020;11:222.

44. Chu CM, Chan VL, Lin AW, Wong IW, Leung WS, Lai CK. Readmission rates and life threatening events in COPD survivors treated with noninvasive ventilation for acute hypercapnic respiratory failure. Thorax 2004;59:1020-5.

45. Cao B et al. A trial of Lopinavir-Ritonavir in adults hospitalized with severe Covid-19. N Engl J Med 2020;382:1787-99.

46. Lim J, Jeon S, Shin HY, Kim MJ, Seong YM, Lee WJ, et al. Case of the index patient who caused tertiary transmission of COVID-19 infection in korea: The application of lopinavir/ritonavir for the treatment of COVID-19 infected pneumonia monitored by quantitative RT-PCR. J Korean Med Sci 2020;35:e79.

47. Meynard JL, Moinot L, Landman R, Morand-Joubert L, Besseghir A, Kolta S, et al.; ANRS 140 DREAM Study Group. Week 96 efficacy of lopinavir/ritonavir monotherapy in virologically suppressed patients with HIV: A randomized non-inferiority trial (ANRS 140 DREAM). J Antimicrob Chemother 2018;73:1672-6.

48. Van Der Laan LE, Garcia-Prats AJ, Schaaf HS, Tikiso T, Wiesner L, DE Kock M, et al. Pharmacokinetics and drug-drug interactions of lopinavir-ritonavir administered with first-and second-line antituberculosis drugs in HIVinfected children treated for multidrug-resistant tuberculosis. Antimicrob Agents Chemother 2018;62:e00420-17.

49. Chan JF, Yao Y, Yeung ML, Deng W, Bao L, Jia L, et al. Treatment with lopinavir/ritonavir or interferon- $\beta 1 \mathrm{~b}$ improves outcome of MERS-cov infection in a nonhuman primate model of common marmoset. J Infect Dis 2015;212:1904-13.

50. Crotty S, Cameron C, Andino R. Ribavirin's antiviral mechanism of action: Lethal mutagenesis? J Mol Med (Berl) 2002;80:86-95.

51. Furuta $Y$, Komeno T, Nakamura T. Favipiravir (T-705), a broad-spectrum inhibitor of viral RNA polymerase. Proc Japan Acad B 2017;93:449-63.

52. Delang L, Abdelnabi R, Neyts J. Favipiravir as a potential countermeasure against neglected and emerging RNA viruses. Antiviral Res 2018;153:85-94.

53. Kadam RU, Wilson IA. Structural basis of influenza virus fusion inhibition by the antiviral drug arbidol. Proc Natl Acad Sci USA 2017;114:206-14.

54. Khamitov RA, Loginova Sla, Shchukina VN, Borisevich SV, Maksimov VA, Shuster AM. [Antiviral activity of arbidol and its derivatives against the pathogen of severe acute respiratory syndrome in the cell cultures]. Vopr Virusol 2008;53:9-13.

55. Wang Z, Yang B, Li Q, Wen L, Zhang R. Clinical features of 69 cases with coronavirus disease 2019 inWuhan, China. Clin Infect Dis 2020. doi:10.1093/cid/ciaa272
56. Dong L, Hu S, Gao J. Discovering drugs to treat coronavirus disease 2019 (COVID-19). Drug Discov Therap 2020;14:58-60.

57. Dong L, Hu S, Gao J. Discovering drugs to treat coronavirus disease 2019 (COVID-19). Drug Discov Ther 2020;14:58-60.

58. Li G, De Clercq E. Therapeutic options for the 2019 novel coronavirus (2019-nCoV). Nat Rev Drug Discov 2020;19:14-150.

59. De Clercq E. New nucleoside analogues for the treatment of hemorrhagic fever virus infections. Chem Asian J 2019;14:3962-8.

60. McCreary EK, Pogue JM. Coronavirus disease 2019 treatment: A review of early and emerging options. Open Forum Infect Dis 2020;7:ofaa105.

61. Chen C, Zhang Y, Huang J, et al. Favipiravir versus arbidol for COVID-19: A randomized clinical trial. medRxiv Posted April 15, 2020. Preprint (not peer reviewed). doi: 10.1101/2020.03.17.20037432

62. Chinese Clinical Trial Registry. Available from: http://www.chictr.org. cn/enindex.aspx. [Last accessed 2020 May 11].

63. Li G, De Clercq E. Therapeutic options for the 2019 novel coronavirus (2019-nCoV). Nat Rev Drug Discov 2020;19:149-50.

64. Lou Y, Liu L, Yao H, et al. Clinical outcomes and plasma concentrations of baloxavir marboxil and favipiravir in COVID-19 patients: An exploratory randomized, controlled trial. medRxiv Posted May 5, 2020. Preprint (not peer reviewed). doi: 10.1101/2020.04.29.20085761

65. Chen I-Y, Moriyama M, Chang M-F, Ichinohe T. Severe acute respiratory syndrome coronavirus viroporin 3a activates the NLRP3 inflammasome. Front Microbiol 2019:10.

66. Schoofs T, Klein F, Braunschweig M, Kreider EF, Feldmann A, Nogueira L, et al. HIV-1 therapy with monoclonal antibody 3BNC117 elicits host immune responses against HIV-1. Science 2016;352:997-1001.

67. U.S. National Library of Medicine. Available from: https://clinicaltrials. gov/ct2/show/NCT04337359. [Last accessed on 2020 May 1].

68. Mehta P, McAuley DF, Brown M, Sanchez E, Tattersall RS, Manson JJ; HLH Across Speciality Collaboration, UK. COVID-19: Consider cytokine storm syndromes and immunosuppression. Lancet 2020;395:1033-4.

69. Giudice V, Pagliano P, Vatrella A, Masullo A, Poto S, Polverino BM, et al. Combination of ruxolitinib and eculizumab for treatment of severe SARS-cov-2-related acute respiratory distress syndrome: A controlled study. Front Pharmacol 2020;11:857.

70. Gaspari V, Zengarini C, Greco S, Vangeli V, Mastroianni A. Side effects of ruxolitinib in patients with SARS-cov-2 infection: Two case reports. Int J Antimicrob Agents 2020;56:106023.

71. Richardson P, Griffin I, Tucker C, et al. Baricitinib as potential treatment for 2019-nCoV acute respiratory disease. Lancet 2020;395:e30-e31.

72. Lilly. Lilly Begins Clinical Testing of Therapies for COVID-19. Press release. Available from: https://investor.lilly.com/news-releases/newsrelease-details/lilly-begins-clinical-testing-therapies-covid-19. [Last accessed on 2020 Apr 10].

73. National Institutes of Health. Coronavirus disease 2019 (COVID-19) Treatment Guidelines. Updated 2020 Jun 11. Available from: https:// www.covid19treatmentguidelines.nih.gov/. [Last accessed on 2020 Jun 23].

74. Xu X, Han M, Li T, et al. Effective Treatment of Severe COVID-19 Patients with Tocilizumab. Available from: chinaXiv. [Last accessed on 2020 Mar 19].

75. COVID-19 Treatment Guidelines Panel. Coronavirus Disease 2019 (COVID-19) Treatment Guidelines. Updated 2020 Jun 11. Available from: https:/www.covid19treatmentguidelines.nih.gov/. [Last accessed on 2020 Jun 26].

76. Aouba A, Baldolli A, Geffray L, et al. Targeting the inflammatory cascade with anakinra in moderate to severe COVID-19 pneumonia: Case series. Ann Rheum Dis 2020 May 6 [Epub ahead of print]. PMID: 32376597. doi: 10.1136/annrheumdis-2020-217706

77. Huet T, Beaussier H, Voisin O, et al. Anakinra for severe forms of COVID-19: A cohort study. Lancet Rheumatol 2020;2:e393-e400.

78. Cavalli G, De Luca G, Campochiaro C, Della-Torre E, Ripa M, Canetti $\mathrm{D}$, et al. Interleukin-1 blockade with high-dose anakinra in patients with COVID-19, acute respiratory distress syndrome, and 
hyperinflammation: A retrospective cohort study. Lancet Rheumatol 2020;2:e325-31.

79. Actemra use in Coronavirus Disease 2019 (COVID-19) Standard Reply Letter. South San Francisco, CA: Genentech; 2020.

80. National Health Commission and State Administration of Traditional Chinese Medicine. Diagnosis and Treatment Protocol for Novel Coronavirus Pneumonia (Trial Version 7). (Mandarin; English translation.) 2020 Mar 3.

81. Haagmans BL, Kuiken T, Martina BE, Fouchier RA, Rimmelzwaan GF, van Amerongen G, et al. Pegylated interferon-alpha protects type 1 pneumocytes against SARS coronavirus infection in macaques. Nat Med 2004;10:290-3.

82. Lau SKP, Lau CCY, Chan KH, Li CPY, Chen H, Jin DY, et al. Delayed induction of proinflammatory cytokines and suppression of innate antiviral response by the novel middle east respiratory syndrome coronavirus: Implications for pathogenesis and treatment. J Gen Virol 2013;94:2679-90.

83. Falzarano D, de Wit E, Martellaro C, Callison J, Munster VJ, Feldmann H. Inhibition of novel $\beta$ coronavirus replication by a combination of interferon- $\alpha 2 b$ and ribavirin. Sci Rep 2013;3:1686.

84. Falzarano D, de Wit E, Rasmussen AL, Feldmann F, Okumura A, Scott DP, et al. Treatment with interferon- $\alpha 2 \mathrm{~b}$ and ribavirin improves outcome in MERS-cov-infected rhesus macaques. Nat Med 2013;19:1313-7.

85. Hung IF, To KK, Lee CK, Lee KL, Chan K, Yan WW, et al. Convalescent plasma treatment reduced mortality in patients with severe pandemic influenza A (H1N1) 2009 virus infection. Clin Infect Dis 2011;52:447-56.

86. Bloch EM, Shoham S, Casadevall A, Sachais BS, Shaz B, Winters JL, et al. Deployment of convalescent plasma for the prevention and treatment of COVID-19. J Clin Invest 2020;130:2757-65.

87. Tiberghien $\mathrm{P}$, de Lambalarie $\mathrm{X}$, Morel $\mathrm{P}$, et al. Collecting and evaluating convalescent plasma for COVID-19 treatment: Why and how. VOX 2020. Epub. doi: 10.1111/vox.12926.

88. Roback JD, Guarner J. Convalescent plasma to treat COVID-19: Possibilities and challenges. Editorial. JAMA 2020;323:1561-62.

89. Casadevall A, Pirofski LA. The convalescent sera option for containing COVID-19. J Clin Invest 2020;130:1545-8.

90. Cunningham AC, Goh HP, Koh D. Treatment of COVID-19: Old tricks for new challenges. Crit Care 2020;24:91.

91. Madariaga MLL, Guthmiller JJ, Schrantz S, et al. Clinical predictors of donor antibody titer and correlation with recipient antibody response in a COVID-19 convalescent plasma clinical trial. medRxiv. Available from: (https://www.medrxiv.org/content/10.1101/2020.06.21.2013294 4v1). [Last accessed on 2020 Jun 23].

92. Zhao JP, Hu Y, Du RH, Chen ZS, Jin Y, Zhou M, et al. [Expert consensus on the use of corticosteroid in patients with 2019-ncov pneumonia]. Zhonghua Jie He He Hu Xi Za Zhi 2020;43:E007.

93. Zhou CG, P CH, Hersh AR, Caughey AB. Antenatal corticosteroids for pregnant women with COVID-19 infection and preterm prelabor rupture of membranes: A decision analysis. J Mater Fetal Neonatal Med 2020:1-9.

94. WHO. Clinical Management of Severe Acute Respiratory Infection (SARI) when COVID-19 Disease is Suspected. Interim guidance. Available from: https://www.who.int/docs/default-source/coronaviruse/clinicalmanagement-of-novel-cov.pdf. [Last accessed on 2020 Mar 13].

95. World Health Organization. Clinical Management of COVID-19. Interim guidance. Updated 2020 May 27. Availalbe from: https:/www.who.int/ publications-detail/clinical-management-of-severe-acute-respiratoryinfection-when-novel-coronavirus-(ncov)-infection-is-suspected. [Last accessed on 2020 Jul 1].

96. Centers for Disease Control. Healthcare Professionals: Frequently Asked Questions and Answers. Updated 2020 Jun 28. Available from: https:// www.cdc.gov/coronavirus/2019-ncov/hcp/faq.html. [Last accessed on 2020 Jul 1].
97. Lamontagne F, Rochwerg B, Lytvyn L, Guyatt GH, Møller MH, Annane D, et al. Corticosteroid therapy for sepsis: A clinical practice guideline. BMJ 2018;362:k3284.

98. Lewis SR, Pritchard MW, Thomas CM, et al. Pharmacological agents for adults with acute respiratory distress syndrome (Review). Cochrane Database Syst Rev 2019;7:CD004477.

99. Caly L, et al. The FDA-approved drug ivermectin inhibits the replication of SARS-CoV-2 in vitro. Antivir Res 2020;178:104787.

100. Gautret P, Lagier JC, Parola P, Hoang VT, Meddeb L, Mailhe M, et al. Hydroxychloroquine and azithromycin as a treatment of COVID-19: Results of an open-label non-randomized clinical trial. Int J Antimicrob Agents 2020;56:105949.

101. Bosseboeuf E, Aubry M, Nhan T, Pina J, Rolain J, Raoult D, Musso D. Azithromycin inhibits the replication of zika virus. J Antivir Antiretroviral 2018;10:6-11.

102. WHO. Clinical Management of COVID-19. Interim Guidance. Available from: ///C:/Users/hp/Desktop/WHO-2019-nCoV-clinical-2020.5-eng.pdf. [Last accessed on 2020 May 27].

103. Simpson RJ, Kunz H, Agha N, Graff R. Exercise and the regulation of immune functions. Prog Mol Biol Trans Sci. 2015;135:355-80.

104. Chan KW, Wong VT, Tang SCW. Covid-19: An update on the epidemiological, clinical, preventive, and therapeutic evidence and guidelines of integrative Chinese-western medicine for the management of 2019 novel coronavirus disease. Am J Chin Med 2020;48:737-62.

105. National Health Commission Press conference of the joint prevention and control mechanism of the State Council on. Available from: http:// www.nhc.gov.cn/xcs/fkdt/202004/05f7318e9fb84b419b35559bc02a4 2f4.shtml. [Last accessed on 2020 Apr 14].

106. WHO. Clinical Management of Severe Acute Respiratory Infection When Novel Coronavirus [nCoV] Infection is Suspected. Available from: https://www.who.int/publications-detail/clinical-managementof-severe-acute-respiratory-infection-when-novelcoronavirus-[ncov]infection-is-suspected. [Last accessed on $2020 \mathrm{Feb} 9$ ].

107. Arabi YM, Shalhoub S, Mandourah Y, Al-Hameed F, Al-Omari A, Al Qasim E, et al. Ribavirin and interferon therapy for critically ill patients with middle east respiratory syndrome: A multicenter observational study. Clin Infect Dis 2020;70:1837-44.

108. Stockman LJ, Bellamy R, Garner P. SARS: Systematic review of treatment effects. PLoS Med 2006;3:e343.

109. NHC. Guidelines for the Prevention, Diagnosis, and Treatment of Novel Coronavirus-induced Pneumonia. 5th ed. National Health Commission; 2020.

110. Chang D, Xu H, Rebaza A, Sharma L, Dela Cruz CS. Protecting healthcare workers from subclinical coronavirus infection. Lancet Respir Med 2020;8:e13.

111. Gostic KM, Kucharski AJ, Lloyd-Smith JO. Effectiveness of traveller screening for emerging pathogens is shaped by epidemiology and natural history of infection. Elife 2015;4:e05564.

112. Corrêa TD, et al. Fluid therapy for septic shock resuscitation: Which fluid should be used? Einstein 2015;13:462-8.

113. Rhodes A, Evans LE, Alhazzani W, Levy MM, Antonelli M, Ferrer R, et al. Surviving Sepsis Campaign: International Guidelines for Management of Sepsis and Septic Shock: 2016. Intensive Care Med 2017;43:304-77.

114. Weiss SL, Peters MJ, Alhazzani W, Agus MSD, Flori HR, Inwald DP, et al. Surviving sepsis campaign international guidelines for the management of septic shock and sepsis-associated organ dysfunction in children. Pediatr Crit Care Med 2020;21:e52-e106.

115. WHO. Pocketbook of Hospital Care for Children: Guidelines for the Management of Common Childhood Illnesses. Geneva, Switzerland: World Health Organization; 2013.

116. Bridwell RE, Carius BM, Long B, Oliver JJ, Schmitz G. Sepsis in pregnancy: Recognition and resuscitation. West J Emerg Med 2019;20:822-32. 